Published in "Molecular and Cellular Neuroscience 28: 75- 291, 2005" which should be cited to reference this work.

\title{
Cocaine-Induced Expression Changes of Axon Guidance Molecules in the Adult Rat Brain
}

\begin{abstract}
Amine Bahi, and Jean-Luc Dreyer
Institute of Biochemistry, University of Fribourg, Chemin du Musée 5, CH-1700 Fribourg, Switzerland
\end{abstract}

Address for Correspondence: Prof. Jean-Luc Dreyer

Institute of Biochemistry

University of Fribourg

Chemin du Musée 5

$\mathrm{CH}-1700$ Fribourg

E-Mail: jean-luc.dreyer@unifr.ch

Tel: $++41-26-300 ' 8632$

FAX: $++41-26-300^{\prime} 9735$

Running title: "Cocaine-induced Plasticity and Regulation of Axon Guidance Molecules"

Corresponding Author: Prof Jean-Luc Dreyer, Institute of Biochemistry, University of Fribourg, Chemin du Musée 5, CH-1700 Fribourg, Switzerland Phone ++41-26-300-8632 FAX ++41-26-300-9735 jean-luc.dreyer@unifr.ch

Acknowledgements: Supported in part by Swiss National Foundation grants 31-53206.97 and 3100-059350.99/1 (JLD).

KEYWORDS: COCAINE, DRUGS OF ABUSE, SEMAPHORIN, EPH, EPHRIN, PLASTICITY, AXON GUIDANCE, DNA-MICROARRAY, QUANTITATIVE REAL-TIME PCR 


\begin{abstract}
Administration of drugs of abuse induces strong molecular adaptations and plasticity within the mesolimbic dopamine (DA) system, a pathway essential for reward-seeking behavior. Little is known about the specific targets involved in this neuroadaptation process, but there are indications that cocaine and other drugs of abuse share the ability to alter the morphology of neuronal dendrites and spines, the primary site of excitatory synapses in the brain. Axon guidance molecules, the very molecular cues that regulate the formation of axon-target connections during development, may mediate these alterations. To test this hypothesis, we investigated mRNA expression changes of 39 axon guidance molecules, including 17 Semaphorins, 12 Ephs, 8 Ephrins and 2 neuropilins in the mesolimbic dopamine system of cocaine-treated animals under different paradigms by mean of DNA-Microarray and quantitative real-time PCR. In all cases, strong changes in gene expression are observed, yielding to up or down-regulation of these axon guidance molecules. Our data suggest that cocaine treatment induces activation of a complex program of synaptic rearrangements, which may partly recapitulate the plastic changes occurring during development, and may underlie the important neuroplastic adaptations that occur in the reward- and memory-related brain centers following drug action. We conclude that in some brain regions, exposure to psychomotor-stimulant drugs produce expression changes in axon guidance molecules, which may contribute to cognitive deficits associated with drug abuse.
\end{abstract}




\section{INTRODUCTION}

Repeated exposure to drugs of abuse induces complex rewiring of neural circuitry that results in the behaviors associated with addiction (Chao and Nestler, 2004, Nestler 2000, Berke et al., 1998). Molecular adaptations following acute and chronic drug administration involve the mesolimbic dopamine (DA) system as the primary site affected in drug dependence and underlies strong plasticity in response to the drug (Schultz, 1998). Addictive drugs (cocaine and amphetamines), depressants (ethanol) and opiate narcotics (heroin and morphine) are very powerful reinforcers and produce their rewarding effects of euphoria or pleasure through an interaction with the mesolimbic DA system (Nestler, 1997). Within the tegmental area, interaction between neurotrophic factors or cytokines and drugs of abuse has been well established (Berhow et al., 1996; Nestler et al., 1996). CNTF mimics some of the long-term effects of cocaine and opiates in the tegmentum through its GP130 receptor (Ip and Yancopoulos, 1996), which triggers the JAK-STAT pathway. There is also evidence for drug-regulated alterations of glial cells in the tegmentum ( $\mathrm{O}^{\prime}$ Callaghan and Miller, 1994). Major known neuronal adaptations include intracellular down-stream changes, such as decreases in Gi $\alpha$ and Go $\alpha$ levels, changes in the cAMP pathway (Nestler et al., 1990), increases in tyrosine hydroxylase levels, and altered expression of transcription factors ( $\triangle \mathrm{fosB}$ ) (Nestler et al., 1999, Moratalla et al, 1996, Moratalla et al., 1993), neurofilaments and phosphoproteins ( $\alpha$-internexin, NF-66) (SklairTavron 1996, Beitner-Johnson, 1992). Perturbation in the BDNF signaling cascade, yielding an increase of extracellular signal regulated kinase (ERK) and tyrosine hydroxylase induction has also been reported (Sklair-Tavron 1996; Berhow et al., 1995).

However alterations at synapses - a key process in drug-related plasticity - may be guided by the expression of axon guidance molecules (Grünwald, 2004, Gosh, 2002, Goldenschwegge et al., 2002, Atwal et al., 2004, Pasquale, 2000). Semaphorins might significantly contribute to the maintenance and stability of neuronal networks and play important roles in the regeneration, or failure thereof, of 
neuronal connections (De Wit and Verhaagen, 2003). Eph receptors are involved in synaptic plasticity (Grünwald et al, 2001, Henderson et al, 2001) and several Eph molecules are upregulated after injury (Willson et al, 2002, Battaglia et al, 2003, Knöll et al, 2001). Nevertheless little is known about cell surface molecules involved in neuroadaptations after drug intake. Strong induction of a surface tetraspanin protein, CD81, has been described (Michna et al., 2001, Halladay et al., 2000, Brenz-Verca et al., 2001, Bahi et al., 2004). Also specific axon guidance cues, such as EphB1 and ephrin-B2, are expressed after challenges with psychomotor stimulants, (Zhou, 1998; Yue et al., 1999). These two complementary cues guide neurons during the development of the central nervous system for the establishment of topographic projections in the mesolimbic dopaminergic pathway (Yue et al., 1999), suggesting that the very cues that attract, repulse or hem axon growth cones on their way to their synaptic targets, are re-expressed in the adult brain after a drug challenge to the CNS. Alterations at synapses might therefore be guided by the very molecular cues that formed the projection-target connections during development. Based on this suggestion, we further tested this hypothesis on a large number of axon guidance molecules, namely the semaphorins and their cognate receptors, the neuropilins, and the Eph receptor tyrosine kinases and their cognate ligands, the Ephrins.

The semaphorins are among the best-studied axonal guidance molecules and appear to play key roles in these cellular events (Bagri et Tessier-Lavigne, 2002, Atwal et al., 2004, Püschel et al., 2002, Wit and Verhaagen, 2003). To date, more than 20 different semaphorins have been identified. They fall into eight groups on the basis of domain organization and species of origin, but all semaphorins contain a conserved, 500-amino-acid-length "Sema" domain at their amino-terminus (Püschel et al, 2002). This domain is also present in the plexin (Plex) family (Püschel et al, 2002). The other family of axon guidance molecules investigated in this study, the Eph receptors and ephrin ligands, have provided important insights into the molecular mechanisms underlying cellular interactions regulating axon guidance, cell migration, and morphogenesis (Flanagan and Vanderhagen, 1998). Interactions between ephrins and Ephs require 
cell-cell contact, thereby raising the intriguing possibility that in some developmental contexts, signaling is bidirectional (Osterfield et al., 2003).

We investigated the expression of these guidance cues in the mesolimbic dopamine system of cocaine-treated animals under various paradigms by means of DNA-Microarrays and quantitative real-time PCR. Drastic and complex changes in expression observed upon cocaine administration are discussed. 


\section{EXPERIMENTAL PROCEDURES}

\section{Animal Handling}

Subjects used in this experiment were male Wistar rats weighing 225$250 \mathrm{~g}$ (BRL, Fillingsdorf, Switzerland). All animal experiments were carried out in accordance with the guidelines and regulations for Animal Experimentation, BAG, Bern, Switzerland. The animals were housed in trios in clear plastic cages with wire grid lids. Access to food and water was unrestricted. The animals were kept in the animal facility maintained on a 12-h light: 12-h dark cycle (lights off at 19:00 h).

Drug administration Protocols: Four different protocols were used in this study, depicted in Figure 1. These protocols represent different paradigms of drug administration, based on established methodologies and allow for good evaluation of drug-induced expression changes and pattern correlation among the various candidates. These included (a) an acute treatment, consisting of a single dose of cocaine $(15 \mathrm{mg} / \mathrm{kg}$, i.p.); (b) a binge treatment consisting of four high doses $(30 \mathrm{mg} / \mathrm{kg}$ i.p.) at two hours interval within a single day (c) a chronic treatment, consisting of a daily dose of cocaine (15 mg/kg i.p. over 15 days); and (d) a sensitization protocol subdivided into four test groups. After sacrifice, four brain regions were dissected out (Hippocampus, Nucleus Accumbens, Striatum and Ventral Tegmental Area), the total RNA was extracted, amplified, labeled and hybridized onto microarrays. The remaining RNA was reverse transcribed for quantitative real-time PCR.

Acute Paradigm: rats $(\mathrm{n}=6)$ were i.p. injected once with $15 \mathrm{mg} / \mathrm{kg}$ cocaine-HCl (Sigma Chemical Co., Buchs, Switzerland). Control animals received $0.9 \%$ saline i.p. injection. All the animals were sacrificed $24 \mathrm{~h}$ after the last injection by decapitation

Binge Paradigm: rats $(\mathrm{n}=6)$ were i.p. injected with $30 \mathrm{mg} / \mathrm{kg}$ cocaine$\mathrm{HCl}$ (Sigma Chemical Co., Buchs, Switzerland) every 2 hours for 4 injections. Control animals received $0.9 \%$ saline i.p. injection under the same schedule. All the animals were sacrificed $24 \mathrm{~h}$ after the last injection by decapitation

Chronic Paradigm: rats $(\mathrm{n}=6)$ were daily i.p. injected with $15 \mathrm{mg} / \mathrm{kg}$ cocaine-HCl (Sigma Chemical Co., Buchs, Switzerland) for a period 
of 15 days. Control animals received $0.9 \%$ saline i.p. injection under the same schedule. All the animals were sacrificed 24 hours after the last injection by decapitation

Sensitization Paradigm (see Figure 1 for samples identification): Four groups ( $\mathrm{n}=6$ per group) were used. Groups $\mathbf{S 1}$ and $\mathbf{S 2}$ represent control groups, treated with saline during an initial period, when groups S3 and S4 received cocaine over five days of sensitization. After a short withdrawal period (3 days, groups S1 and S3) or a long withdrawal period (14 days, groups S2 and S4), animals were challenged and sacrificed $24 \mathrm{~h}$ later

S1 and S2 groups: rats were treated ("sensitized") with daily i.p. injections of $0.9 \%$ saline during 5 days. On the $3^{\text {rd }}$ day (group S1) or on the $14^{\text {th }}$ day (group S2) after the last administration ("sensitization"), half of the groups were challenged with a single i.p. injection of $0.9 \%$ saline and the other half with a single i.p. injection of $15 \mathrm{mg} / \mathrm{kg}$ cocaine- $\mathrm{HCl}$ (Sigma Chemical Co., Buchs, Switzerland). Groups were sacrificed by decapitation $24 \mathrm{~h}$ later, on the $4^{\text {th }}$ and the $15^{\text {th }}$ days for groups $\mathbf{S 1}$ and $\mathbf{S 2}$, respectively.

For the S3 and S4 groups: rats were sensitized with daily i.p. injections of $15 \mathrm{mg} / \mathrm{kg}$ cocaine- $\mathrm{HCl}$ (Sigma Chemical Co., Buchs, Switzerland) during 5 days. On the $3^{\text {rd }}$ day (group S3) or on the $14^{\text {th }}$ day (group S4) after the last sensitization, half of the groups were challenged with a single i.p. injection of $0.9 \%$ saline and the other half with a single i.p. injection of $15 \mathrm{mg} / \mathrm{kg}$ cocaine- $\mathrm{HCl}$ (Sigma Chemical Co.). Groups were sacrificed by decapitation $24 \mathrm{~h}$ later, on the $4^{\text {th }}$ and the $15^{\text {th }}$ days for groups S3 and S4, respectively.

\section{RNA Preparation and Microarray Hybridization}

RNA Extraction: After sacrifice, brain regions were dissected out (Hippocampus, Nucleus Accumbens, Striatum and Ventral Tegmental Area), and the total RNA was extracted. In all cases brain regions were pooled before preparing RNA, since previous control experiments with unpooled samples had shown no statistical differences compared to pooled samples.

Total RNA was isolated using RiboPure Kit (Ambion, UK) according to the manufacturer's protocol. Briefly, $1 \mathrm{ml}$ of RNAwiz was added to $50 \mathrm{mg}$ of tissue, homogenized with a Polytron homogenizer, vortexed 
for $30 \mathrm{~s}$ and incubated at room temperature for $5 \mathrm{~min}$. Residual protein was removed by the addition of $0.2 \mathrm{ml}$ of chloroform, mixing for $30 \mathrm{~s}$, incubation at room temperature for $5 \mathrm{~min}$, vortexing for further $30 \mathrm{~s}$, and centrifugation for $15 \mathrm{~min}$ at $12000 \mathrm{~g}$ and room temperature. The aqueous phase was precipitated with $0.5 \mathrm{ml}$ of absolute ethanol, filtered over a column and washed by centrifugation. The total RNA was then eluted with $0.1 \mathrm{ml}$ of DEPCtreated water, incubated at $60^{\circ} \mathrm{C}$ for $10 \mathrm{~min}$ and stored at $-80^{\circ} \mathrm{C}$.

RNA Amplification: This was performed according to Kacharmina et al. (1999). First Strand Synthesis was performed in $0.2 \mathrm{ml}$ RNAse-free PCR tubes as follows: $2 \mu \mathrm{g}$ of total RNA was added to $9 \mu \mathrm{l}$ of $0.6 \mathrm{M}$ Trehalose in DEPC water and $1 \mu \mathrm{g}$ Eberwine oligo-dT/T7 primer (5'AAA CGA CGG CCA GTG AAT TGT AAT ACG ACT CAC TAT AGG CGC T15-3'). These components were mixed well by pipetting and heated at $65^{\circ} \mathrm{C}$ for 10 minutes, then kept on ice. To the mixture 4 $\mu \mathrm{l}$ of 5X First Strand Buffer (Invitrogen, Basel, Switzerland) was added, followed by $2 \mu \mathrm{l}$ 0.1M DTT, $10 \mathrm{U}$ RNAsin (Invitrogen, Basel, Switzerland), 1 Hl 10 mM dNTP mix (Promega, Wallisellen, Switzerland), $1 \mu$ linear acrylamide $(0.1 \mathrm{mg} / \mathrm{ml}), 1 \mu \mathrm{l} 200 \mathrm{U} / \mu \mathrm{l}$ Superscript II RNaseH-Reverse Transcriptase (Invitrogen, Basel, Switzerland). The mixture was incubated in a thermocycler at: $37^{\circ} \mathrm{C}$, $5 \mathrm{~min} ; 45^{\circ} \mathrm{C}, 5 \mathrm{~min}$; then 25 cycles alternating between $60^{\circ} \mathrm{C}, 2 \mathrm{~min}$ and $55^{\circ} \mathrm{C}, 2 \mathrm{~min}$. Tubes were kept on ice, while adding second strand components. Second Strand Synthesis was followed by adding $106 \mu \mathrm{l}$ DEPC water, $15 \mu \mathrm{l}$ Second Strand Buffer [200 mM Tris pH 6.9, 900 $\mathrm{mM}$ potassium chloride, $46 \mathrm{mM}$ magnesium chloride, $1.5 \mathrm{mM}$ Nicotine Adenine Dinucleotide (Calbiochem, Nottingham, UK), 100 $\mathrm{mM}$ ammonum sulfate, $3 \mu \mathrm{l} 10 \mathrm{mM}$ dNTP mix (Promega, Wallisellen, Switzerland), 10 U E. coli DNA Ligase (Bioconcept, Allschwill, Switzerland), 30 U E. coli DNA Polymerase I-holoenzyme (Bioconcept, Allschwill, Switzerland), 2 U RNase H (Invitrogen, Basel, Switzerland). The mixture was incubated at $16^{\circ} \mathrm{C}$ for 4 hours. The reaction was stopped with $7.5 \mu \mathrm{l} 1 \mathrm{M} \mathrm{NaOH} / 2 \mathrm{mM}$ EDTA with incubating at $65^{\circ} \mathrm{C}$ for 10 minutes. The double-stranded DNA was extracted once with Phenol:chloroform:isoamyl (25:24:1). $150 \mu \mathrm{l}$ of organics were added directly to PCR tubes, mixed and centrifuged 
for $5 \mathrm{~min}$ at $15^{\prime} 000 \mathrm{~g}$ at room temperature. The aqueous phase was transferred to Rnase-free 1.5 1 Eppendorf tube and DNA was precipitated with $70 \mu \mathrm{l}$ of $7.5 \mathrm{M}$ ammonium acetate (in DEPC-water, 0.2 micron filtered) and $1 \mathrm{ml}$ absolute ethanol $\left(-20^{\circ} \mathrm{C}\right)$. Tubes were vortexed and centrifuged immediately for $20 \mathrm{~min}$ at $15^{\prime} 000 \mathrm{~g}$ at room temperature. The pellet was washed once with $100 \mu \mathrm{l}$ absolute ethanol and resuspended in $10 \mu \mathrm{l}$ of DEPC-water. In vitro transcription was then performed with the Ambion T7 Megascript Kit (Ambion, UK), according to the manufacturer's protocol.

Probe Preparation and Hybridisation: Each aRNA sample (one from control sample and one from treated sample) was reverse-transcribed in the presence of Cy3-dCTP (control samples) or Cy5-dCTP (treated samples) (Amersham Pharmacia Biotech, Dübendorf, Switzerland). Each reaction was performed in a $30 \mu \mathrm{l}$ volume containing $2 \mu \mathrm{g}$ of aRNA, $2 \mu \mathrm{g}$ of oligo(dT) 21-mer, $500 \mu \mathrm{M}$ each of dATP, dGTP, and dTTP, $200 \mu \mathrm{M}$ dCTP, $100 \mu \mathrm{M}$ Cy3-dCTP or Cy5-dCTP, 30 units of RNase inhibitor, 10 M DTT, and 400 units of SuperScriptII reverse transcriptase (Invitrogen, Basel, Switzerland) in SuperScript buffer. After incubation at $42^{\circ} \mathrm{C}$ for 3 hours, the sample tubes containing Cy3 and Cy5 labeling were pooled and treated with $2.65 \mu \mathrm{l}$ of $25 \mathrm{mM}$ EDTA and $3.3 \mu \mathrm{l}$ of $1 \mathrm{M} \mathrm{NaOH}$ for $10 \mathrm{~min}$ at $65^{\circ} \mathrm{C}$ to degrade the RNA. After the addition of $3.3 \mu \mathrm{l}$ of $1 \mathrm{M} \mathrm{HCl}$ and $5 \mu \mathrm{l}$ of $1 \mathrm{M}$ Tris$\mathrm{HCl}, \mathrm{pH} 6.8$, labeled single stranded DNA was precipitated with 0.1 volume of $3 \mathrm{M}$ sodium acetate and 2 volumes of absolute ethanol, and the pellet was washed with $80 \%$ ethanol, dried, and resuspended in $10 \mu \mathrm{l}$ of hybridization solution containing 3X SSC, $0.2 \%$ SDS, and $0.02 \%$ yeast tRNA (Invitrogen, Basel, Switzerland). Probes were purified by Millipore (Volketswil, Switzerland) Ultrafree-MC filters.

Hybridization Reaction and Microarray Analysis: Before hybridization, the probe solution was boiled for $1 \mathrm{~min}$ and rapidly applied to the microarray under a cover slip. Slides were placed in hybridization chambers, and $20 \mu \mathrm{l}$ of 3X SSC was placed inside each chamber before sealing. Slides were incubated for 14 to 16 hours in a water bath at $64^{\circ} \mathrm{C}$ and washed sequentially in the following solutions: 2X SSC, $0.1 \%$ SDS twice for $5 \mathrm{~min}, 0.2$ XSC twice for $1 \mathrm{~min}$, and $0.1 \mathrm{X}$ SSC twice for $1 \mathrm{~min}$. Slides were dried by centrifugation at 
$900 \mathrm{~g}$ for $2 \mathrm{~min}$ before scanning.

Microarrays were scanned with a scanning laser microscope Affymetrix ${ }^{\circledR} 428^{\mathrm{TM}}$ Array Scanner; (Affymetrix, INC., Santa Clara US). Separate images were acquired for each fluorochrome at a resolution of $10 \mu \mathrm{m}$ per pixel. To normalize the two channels with respect to signal intensity, photomultiplier and laser power settings were adjusted such that the signal ratio of the control genes was as close to 1.0 as possible. The average fluorescence intensity for each fluorochrome and for each gene was determined by using Jaguar 2.0 software (Affymetrix, INC., Santa Clara US). Background fluorescence was calculated as the median fluorescence signal of nontarget pixels around each gene spot. Induction or repression of a gene was defined as a minimum 1.5-fold change in its transcript level.

Statistical Evaluation of Microarray data: Signal intensities of spots corresponding to a given candidate from three independent tissue samples, with mean standard deviation, were plotted as cocainetreated versus saline-treated probes. Quantification was presented as the ratio between experiments (Cy5-labeled samples) versus control (Cy3-labeled samples) changes in expression at mRNA level, after background substraction. The raw data were initially analyzed using Jaguar 2.0 (Affymetrix, INC., Santa Clara US), which calculates normalized expression levels and generates ratios of experimental (Cy5) versus control (Cy3) signals. Then data sets from comparison files were imported into Excel (Microsoft) for further analysis and pvalues calculations. A stringent cut-off was used for significance: genes were considered to be down regulated if the ratio of experimental vs. control was $\leq 2.0$ (with $p<0.01$ ) and up-regulated if the ratio was $\geq 2$ (with $\mathrm{p}<0.01$ ). Significance was calculated using a ttest (McClung and Nestler, 2003).

\section{Microarray Design}

Selected Gene Candidates (see Table 1): Microarray design was performed according to published methods (Shalon et al., 1996). 20 control oligonucleotides were included consisting of 10 negative controls (oligonucleotides randomly generated with no expression within neither the mouse nor the rat genomes) and 10 positive controls: $\beta$-Actin ( $\left.\underline{\mathrm{NM} \_031144}\right)$, Transcription factor E2 $\alpha$ ( $\left.\underline{\mathrm{X17500}}\right)$, 
Lactate dehydrogenase A (NM_017025), Hsp70-1 (NM_031971), Nuclear pore glycoprotein 62 (M62992), Ribophorin 20814 (NM_031698), Ribosomal protein L5 (NM_031099) Ribosomal protein S9 (NM_031108, glyceraldehyde-3-phosphate dehydrogenase (GAPDH) (NM_017008) and Polyubiquitin (D16554). The means of values of the negative controls were considered as background and subtracted from all other data. Besides these positive and negative control oligonucleotides, the microarray included oligonucleotides corresponding to the 39 axon guidance gene candidates selected for this study, which are listed in Table 1. These were 17 members of the Semaphorin family, 2 members of their corresponding receptors (Neuropilin 1 and Neuropilin 2), 12 members of the Eph Receptor Tyrosine Kinase (7 members of the EphA family and 5 members of the EphB family) and 8 members of their corresponding Ephrin ligands (5 Ephrin-A and 3 Ephrin-B). Candidates, including gene ID and oligonucleotide sequences and BLAST reference are listed in Table1. Note: Oligonucleotides sequences of positive and negative controls are patented (QIAGENTM, Basel, Switzerland) and are not listed. 
Specific oligonucleotides were designed (see below $)$ and sythetized with $5^{\prime}$-amino modification. Oligonucleotides were resuspended in 1.5 M Betaine, 3X SSC to a final concentration of $40 \mu \mathrm{M}$ and then arrayed (8 spots/oligo) onto QMT Aldehyde Slides (Quantifoil, Germany) by using a high precision OmniGrid Accent ${ }^{\mathrm{TM}}$ Microarrayer (GeneMachines, San Carlos, CA) equipped with four printing tips. Each candidate was spotted eight fold, providing hybridization replicates on the same slide. After printing, slides were allowed to dry, and unbound DNA was removed with $0.2 \%$ SDS and double-distilled water; covalently bound DNA was denatured for 2 min in boiling water. Free aldehydes were reduced by soaking slides for $5 \mathrm{~min}$ in $68 \mathrm{mM}$ Sodium Borohydride (dissolved in PBS containing $25 \%$ ethanol). Several washing steps were performed with $0.2 \%$ SDS and double-distilled $\mathrm{H} 2 \mathrm{O}$; then slides were dried by centrifugation at $500 \mathrm{~g}$ for $5 \mathrm{~min}$ and stored at room temperature for further hybridizations.

\section{Probe design and selection rules (QIAGEN ${ }^{\mathrm{TM}}$, Basel, Switzerland):}

For each selected gene candidate, several 70 mer probes were designed. Each probe was sequence optimized using BLAST (Basic Local Alignment Search Tool) for nucleotide sequence to minimize cross hybridization in the microarray experiments. The 70 mers were also Tm-normalized to $78^{\circ} \mathrm{C}\left( \pm 5^{\circ} \mathrm{C}\right)$ for a more stringent hybridization at higher temperatures. Where 70mers could not be designed within the specified $\mathrm{Tm}$ range, shorter- or longer-length oligos were substituted to maintain the stringent $T m$ conditions. In addition, each 70mer was flanked by a 5' C6 amino linker. Designed oligo were chosen within 1000 bases from the $3^{\prime}$ end of the gene sequence such as excluding contiguous single nucleotide base repeats, poly $(\mathrm{N})$ tracts longer than 10 bases or hairpin structures with a stem-length longer than 9 bases. A normalized score was assigned to each oligo, based on the number of repeats, and with $\leq 70 \%$ identity to all other genes. Using BLAST, each oligo was aligned against all 59,018 representative sequences in Rat UniGene Build Rn 90 and 62,758 representative sequences in Rat UniGene Build Rn 108. Using the alignment with the candidate oligo versus the highest scoring nonself gene, a BLAST percent identity score was computed, defined as the sequence that yielded the most matched bases in an alignment. 
This BLAST percent identity was also referred to as crosshybridization identity of the oligo. This calculated crosshybridization identity was dependent on the size of the sequence database used to BLAST against oligo sequence, and the use of either gapped or no-gap alignment method. Furthermore, oligos could not have greater than 20 contiguous bases common to any other gene. Once oligo candidates were designed, satisfying all selection rules mentioned above, each oligo was ranked based on BLAST percent identity and one final oligo for each gene was selected with minimum percent identity or cross hybridization similarity.

\section{Real-Time PCR and mRNA Quantification}

Total RNA was isolated from different brain regions using RiboPure Kit (Ambion, UK), according to the manufacturer's protocol including a RNase-free DNase step, and stored at $-80^{\circ} \mathrm{C}$. RNA were quantified by spectrophotometry. Integrity of the RNA was verified by agarose gel electrophoresis and visualized with ethidium bromide staining. First strand cDNA was synthesized using $1 \mu \mathrm{g}$ of total RNA and Oligo(dT) primers with the M-MLV reverse transcription kit (Invitrogen, Basel, Switzerland) in a total volume of $15 \mu \mathrm{l}$.

Real-time PCR was performed to confirm Microarray results. Primer sets were designed to amplify 100 - to $300-b p$ products, using PRIMER3 software

(http://frodo.wi.mit.edu/cgi-bin/primer3/primer3_www.cgi).

To quantify expression of cDNAs the real-time PCR iCycler (BioRad, Reinach, Switzerland) was used. For PCR, $5 \mu$ l cDNA preparation, $0.5 \mu \mathrm{M}$ of forward and reverse primers and $10 \mu \mathrm{l}$ of IQ SYBR Green Supermix (Biorad, Reinach, Switzerland) in a total volume of $20 \mu \mathrm{l}$ were applied. The following PCR program was performed: $3 \mathrm{~min}$ at $95^{\circ} \mathrm{C}$ (initial denaturation); $20^{\circ} \mathrm{C} / \mathrm{sec}$ temperature transition rate up to $95^{\circ} \mathrm{C}$ for $30 \mathrm{sec}, 45 \mathrm{sec} 62^{\circ} \mathrm{C}$, repeated for 40 times (amplification). The PCR reaction was evaluated by melting curve analysis following the manufacturer's instructions and checking the PCR products on $2 \%$ agarose gel.

The PCR cycle number at which each assay target reached the threshold detection line was determined ( $\mathrm{Ct}$ value). cDNA samples were assayed on at least 3 dilutions to check for assay reliability 
using duplicate assay on each dilution. The $\Delta \mathrm{Ct}$ for each candidate was calculated as $\Delta \mathrm{Ct}=[\mathrm{Ct}$ (candidate) $-\mathrm{Ct}$ (GAPDH or $\beta$-Actin)]. The relative abundance of each target in each protocol can be calculated as the ratio between treated and untreated samples (Mühlbauer et al., 2004).

GAPDH and $\beta$-Actin were used as endogenous controls for normalization. No difference was observed between these two genes for all quantifications (data not shown).

Statistical Analysis: Statistical significance was evaluated by the two-tailed Student's t-test. $\quad \mathrm{P}<0.05$ was considered statistically significant. 


\section{RESULTS}

The aim of this study was to investigate plasticity changes induced by drug administration. Preliminary investigations in our lab, based on differential display with semaphorin-targeted primers, identified several axon guidance molecules as suitable candidates involved in drug-induced neuroadaptations (Widmer, 2000). Based on these findings a microarray was designed, containing 39 guidance cues together with 10 positive and 10 negative control genes (Table 1), with a view of evaluating expression changes in four different brain regions under various paradigms of drug treatment (Figure 1). The results are summarized in Figures 2 and 3. As shown in Figure 2 (upper panel), positive controls displayed no change in expression in the brain areas under investigation, whatever the drug administration protocol: in all cases, the expression ratios of cocainetreated versus saline-treated animals were almost equal to 1.0, with $<8.5 \%$ variation. Data were statistically highly coherent in all brain regions and under any tested condition. Each data represents the average of eight different hybridization slots from three independent tissue samples. Slightly higher variations were observed in the $\mathrm{CPu}$ of acute-treated animals or in chronically treated animals; but such variations were always within very small limits and were supported with very significant statistical correlation for all these control candidates. From these data, a 1.5-fold change in gene expression can be considered as significant. However only two-fold changes or higher will be discussed here.

Drug-induced expression changes of Semaphorin: Expression changes of semaphorins are depicted in Figure 2.

In the hippocampus, six Semaphorins displayed high (2.5 to 8-fold) induction, namely Sema3A, Sema3B, Sema3E, Sema6A, Sema4C and Sema5A. Changes were highest in groups S4 (animals sensitized with cocaine and challenged after long term-withdrawal) or after chronic treatment. Between 8 and 4 -fold up-regulation were observed with these candidates, depending upon regimen, with Sema5A $>$ Sema4C $=$ Sema3E $>$ Sema3B. By contrast Sema3C, Sema6C and Sema4G were strongly down regulated (8- to 4-fold, with Sema4G $>$ Sema6C $>$ Sema3C), mostly after acute treatment. A number of other Semaphorins also displayed expression changes upon 
cocaine, but to a lesser degree. Correspondingly, neuropilin-1 and -2 , which are receptors for soluble semaphorins (Sema3 family members), displayed 2.5 - 4.5 fold up-regulation in this brain region, and the effect was strongest in S4 and chronic groups.

In the Nucleus Accumbens strong down-regulation was observed in many cases, particularly in acute groups. Sema3A, Sema3E, Sema3F, Sema4G, Sema5B and Sema7A displayed >3.5-fold down-regulation after acute treatment and significant down-regulation in all other groups, chronic groups being least affected. Strong up-regulation was observed with most other candidates, particularly after chronic treatment, where $>8$-fold changes were observed (Sema3B $>$ Sema4C $=$ Sema4B $>$ Sema6B $>$ Sema3C $=$ Sema4A $>$ Sema4F).

Two candidates, Sema5A and Sema6A were little affected by cocaine in this region in all protocols. Receptors for soluble Semaphorins, Neuropilin-1 and Neuropilin-2, were also induced in this brain region under all conditions, mainly in chronic groups (ca 5-fold induction).

In the Caudate Putamen, changes were less important. However, some candidates displayed high expression changes: Sema4C was highly up regulated, about 10-fold in S4 groups, 7-fold in chronic groups and 5.5-fold in binge groups. Other candidates displaying strong changes included Sema4A, Sema4B and Sema3E (5-6-fold over expressed in $\mathrm{S} 4$ groups, $>4$-fold in chronic and binge groups) and Sema3F ( $>4$-fold up-regulated in chronic and S4 groups). In contrast Sema4D was about 8-fold down-regulated in acute groups and Sema3A, Sema5B, Sema7A and particularly Sema6C were down regulated (4- to 6-fold, depending upon regimen). Neuropilins were up regulated 3- to 5-fold in all groups.

In the Ventral Tegmental Area, greatest changes were observed with most members of the Sema3, Sema4 and Sema7 and mainly in either acute or in S4 groups. Strong up-regulation was observed generally, but Sema3E and Sema4G were down regulated. In S4 groups, up to $>6$-fold up-regulation was found for Sema3A, Sema3C, Sema4B, and Sema4C, and about 10-fold up-regulation for Sema4D, sema4F and Sema5A. Acute treatment has little effects in expression changes for these candidates, but binge and chronic treatments induce 3-5 fold up-regulation. Down-regulation in this region was highest in acute 
treatments and involved a few candidates: Sema3E (6-fold in acute and S4 groups), Sema4G (7-fold in acute groups), Sema5B and Sema7A (4-fold in acute groups). Sema4A was poorly affected, except in acute treatment (4-fold down-regulation).

In all regions, one candidate (Sema6C) displayed strong downregulation under all protocols whereas Sema4B, Sema4C and neuropilins were up regulated in each region and under all conditions. Furthermore most candidates (except Sema3A, and Sema3F) displayed similar patterns of expression changes both in the Nucleus Accumbens and in the Ventral Tegmental Area the major dopaminergic regions included in this study.

Clearly, the observed expression changes are very consistent, the changes of a single candidate in a given region being very similar, independent of the treatment, with only relative intensities being affected. All the changes observed from microarray data could be confirmed by real-time PCR (Figure 4) and the same pattern of changes was observed in all cases. Figure 4 displays a comparison of the data from qRT-PCR and microarray for major conditions, i.e. where greatest changes in expression were observed (about 15\% of the conditions tested by microarray): in all cases both sets of data matched perfectly. Table 3 displays the statistical analysis of the candidates modified by cocaine on microarray and whose expression change has been confirmed by qRT-PCR. Changes observed in the Nucleus Accumbens on chronically treated animals are very significant for Sema3B, Sema4B, Sema4C and to a lesser extend for Sema3E and NP-1. In the Ventral Tegmental Area most significant changes are observed on chronocally treated animals for Sema3C, and Sema5A, whereas changes observed for Sema3C, Sema3E, Sema3f, Sema4G, Sema5A, Sema5B and NP-1 are highly significant in S4 groups. NP-1 and Sema3E display very significant changes in all regions under most conditions.

Drug-induced expression changes of Eph's and Ephrins: Neuroadaptations after drug treatment also strongly affected expression of Eph's receptor tyrosine kinase and their ligands, as shown in figures 3. Changes are very significant, although less intense for these families of axon guidance molecules. 
In the Hippocampus, all Eph and Ephrins were slightly up regulated. Only in S4 groups and sometimes in acute groups were $>2$-fold upregulations observed for EphA's. For EphB's, changes are $>2$-fold in acute groups as well as in S4 groups. Greatest changes were observed with Eph-B1, EphB4 and EphB2. The corresponding ligands, Ephrins, were also up regulated in all cases, but Ephrin-A's displayed little changes ( $\leq 2$-fold) except in S4 groups (2-4 fold up-regulation). Ephrin-B's, by contrast, were more affected by regimen: S4 and S3 groups displayed ca. 6- and 4-fold up-regulation, respectively while in acute and chronic groups gene expression increased 3-4 fold.

In the Nucleus Accumbens, Eph-A are little affected and $>2$-fold changes were observed only after chronic treatments or sometimes in acute groups (see Eph-A5 and Eph-A8). Their ligands Ephrin-A's displayed comparable adaptation, greatest changes being observed after chronic treatments (about 4-fold up-regulation in all cases). EphB's displayed more important up-regulation: again greatest induction pattern were found after chronic treatments (4-6 fold up-regulation), but acute and binge treatments also strongly affected Eph-B2, Eph-B3 and Eph-B4 (3-5 fold up-regulation). Furthermore, S3 and S4 groups were also strongly affected (4-6 fold up-regulation). Greatest changes were observed with Eph-B4 in all protocols (4-8 fold up-regulation). The corresponding Ephrin-B's ligands were also induced after drug administration under all protocols, mostly after chronic treatment (46 fold up-regulation).

In the Caudate Putamen expression changes of Eph-A and Ephrin-A were more complex. Three Eph-A1, EphA3 and Eph-A5 were down regulated together with their ligands Ephrin-A1 and Ephrin-A3; this effect was most important (6-7 fold down-regulation) after acute treatments for Eph-A1, Eph-A3 and the two Ephrins. By contrast, the other Eph-A's like the other Ephrin-A's were rather over expressed ( $\leq 2$-fold in most cases, but slightly $>2$-fold in $\mathrm{S} 4$ groups). For Eph-B's and Ephrin-B's up-regulation was observed in all cases; this effect was most important for Eph-B4 (4-6 fold up-regulation) and to a lesser extent for Ephrin-B2 and Ephrin-B3.

In the Ventral Tegmental Area, no great changes were observed. Only S4 groups displayed >2-fold changes in Eph-A expression while Ephrin-A's were not much affected either. Ephrin-A1 and Ephrin-A3 
were 3-fold down regulated after acute treatment. For Eph-B3, EphB4 and Eph-B6 also expression was not much changed in this region. By contrast, the other Eph-B's and their corresponding Ephrins displayed stronger induction: with Eph-B1 and Eph-B2, 3-fold upregulation after chronic and binge treatments, and 6-fold upregulation in S4 groups were observed, which matched with 2-4 fold up-regulation and 4-6 fold up-regulation under the same regimen, respectively, of Ephrin-B1 and Ephrin-B2.

Expression changes observed on microarrays for Eph's and Ephrins have been confirmed by means of qRT-PCR. Figure 4 displays the comparison of microarray data and qRT-PCR. For simplicity only the most characteristic expression changes of Eph's and Ephrins in the four brain regions are displayed (representing 14\% of the conditions tested by microarray). As shown in Figure 4, qRT-PCR fully corroborated the changes observed in microarray data, in all cases, without exception, and in most cases the values of the both sets of data matched perfectly. Statistical analysis of changes observed by these candidates (Table 3 ) shows robust changes in the Caudate Putamen under acute treatment for EphA1, EphA2 and their partner ligands EphrinA1 and EphrinA3. Under chronic treatment, most robust changes were observed with EphB's in the Nucleus Accumbens and in the Hippocampus. 


\section{DISCUSSION}

A gene profiling of a number of axon guidance molecule transcripts in several protocols of drug administration has been undertaken in this study, with a view to determine their involvement in druginduced neuroadaptations. These plasticity-related secreted or cell surface molecules are developmentally regulated cues that play a major function during development and direct the projection of the extending axon growth cone to its synaptic target, enabling proper formation of neuronal synapses. A role in the adult brain, however, has been poorly described in a few cases only (De Wit and Verhaagen, 2003). For example, specific re-expression of EphB1 and ephrinB2 was observed in the adult, following a drug challenge (Yue et al., 1999), a finding consistent with the notion that long-term, molecular adaptations of neurons following exposure to drugs of abuse underlie a complex rewiring of neural circuitry that results in the behaviors associated with addiction (Bardo, 1998, Wang and McGinty, 1997, Nestler and Aghajanian, 1997, Robinson and Berridge, 1993). Based on this observation, a gene profiling of two classes of axon guidance molecules, the semaphorins and Ephs/ephrins, was investigated in the present study in different protocols of drug administration.

Drug-induced Plasticity involves Expression Changes of a Combination of Semaphorins and related Receptors: Semaphorins are a large family of secreted, GPI-linked or transmembrane proteins that may bind to neuropilins (secreted Sema-3) and/or plexins and function as chemorepellents or inhibitors of growth cones ( $\mathrm{Yu}$ and Bargmann, 2001, Skoliora et al, 1998). The function of Semaphorins in the adult brain is poorly described, but a role in regeneration of injured nerve fibres is well documented (De Wit and Verhaagen, 2003). During development, different semaphorins are generally co-expressed and interact in synergistic ways, innervation specificity being achieved through the combined action of multiple guidance cues (Steup et al., 1999, Skaliora et al., 1998). For example, during development most striatal and cortical interneurons arise from the basal telencephalon, whose migration is controlled by chemorepulsive signal composed mainly of semaphorin 3A and semaphorin 3F (Marin et al., 2001) and 
migrating interneurons expressing neuropilins are directed to the cortex, while those lacking them go to the striatum. Recent studies have revealed extensive regulation of these cues and their receptors as well as combinatorial mechanisms that integrate information from different families of guidance cues (Yu and Bargmann, 2001). The combinatorial and simultaneous input of multiple guidance cues, i.e. the relative balance of attractive (growth-promoting) and repulsive (growth-inhibiting) forces, provides synapse specificity by allowing axons to select various subsets of nerve cells as their targets.

Our study suggests similar synergistic mechanisms in the adult brain after drug administration: drug-induced plasticity involves the regulation of several semaphorins and their related neuropilin receptors. All members of the five classes of semaphorins included in this study display strong expression changes (>6-fold, except Sema6A and Sema6B) in at least one condition or region, highest changes affecting Sema3A, Sema3B, Sema4B, Sema4C, Sema4F and Sema5A (for nomenclature, see Semaphorin Nomenclature Committee, 1999).

Drug-induced neuroadaptations is known to primarly affect the mesolimbic dopaminergic pathway (Robinson and Berridge, 1993, Nestler, 2000). In this pathway, cocaine induced largest expression changes of many semaphorins, mainly Sema3A, Sema3B, Sema3F, Sema4B, and Sema4C in the Nucleus Accumbens, and Sema3C, Sema3E, Sema4D, Sema4F, Sema4G, Sema5A, Sema5B and Sema7A in the Ventral Tegmental Area.

Sema3 are secreted proteins and act generally as repellents of different classes of axons and their regulation in the adult brain has been described in some disorders. Aberrant expression or signalling of secreted Semaphorins might be of significance in altered structural plasticity in neurodegenerative disorders such as Alzheimer (Good et al, 2002). Sema3A is the most potent repellent and repels axons that are responsive to NGF (Messersmith et al, 2001), but this depends upon the age of the animal (Puschel et al., 1996). Sema3A and its ligand Neuropilin-1 are temporarily down-regulated in the hippocampus in epileptic rat brain, correlating with robust mossy fiber sprouting into the molecular layer, a layer normally devoted of mossy fibers. Kainate-induced status epilepticus also induces a 
persistent down-regulation of Sema3C and Sema3F (Barnes et al., 2003). We found Sema3F to be strongly down regulated in the Nucleus Accumbens after acute treatment and up regulated in other regions, particularly in the Ventral Tegmental Area and the Hippocampus in chronic or S4 groups. This candidate may suppress NGF-induced activation of PI3-kinase-Akt and dampen neutrophin signalling, a novel mechanism of semaphorin-mediated growth cone collapse, providing an intracellular mechanism for cross talk between positive and negative axon growth cues (Atwal et al., 2003).

Sema4C is a transmembrane semaphorin that binds to proteins involved in neurite outgrowth; its strong up-regulation (8-fold) in chronic groups in the Nucleus Accumbens, Hippocampus and striatum may regulate drug-induced plasticity in these areas. Sema4F, which is strongly up regulated after cocaine in the Ventral Tegmental Area, interacts with PSD-95, a scaffold protein which concentrates ion channels, adhesion molecules and neurotransmitter receptors at the post-synaptic membrane (Sheng, 2001). Sema4D associates with cytosolic kinases and binds to proteins involved in neurite outgrowth and cytoskeletal reorganization. These interactions regulate actin dynamics and neurotransmitter receptor clustering, transport and docking of synaptic vesicles and thus modulate spine plasticity (De Wit and Verhaagen, 2003).

Sema5A is a transmembrane protein with seven thrombospondin repeats. It acts as a permissive cue for growing axons (Adams et al., 1996, Neugebauer et al., 1991, Simmons et al, 1998), although a recent report shows that its expression by oligodendrocyte lineage cells contributes to the glial cues that inhibit CNS regeneration. (Goldberg et al., 2004). Sema5A may be responsible for some of the features of the Cri-du-chat syndrome of mental retardation since the gene covers at least 10 percent of the deleted region (Simmons et al., 1998, Inagaki et al., 1995). It is strongly up-regulated (8-fold) in chronic groups in the Hippocampus and to a lesser extend in the Ventral Tegmental Area, but it is down regulated in the striatum.

Sema6C, which is strongly down regulated in all brain regions and in all conditions, is highly expressed in the lateral ventricle, the striatum, the midbrain, the pons/midbrain junction, and the choroid plexus (Qu et al., 2002). Finally, Sema7A, a 
glycosylphosphatidylinositol-linked semaphorin strongly downregulated in the Ventral Tegmental Area after drug treatment, displays highest expression in the nervous system and in the adult brain (Sato and Takahashi, 1998, Xu et al., 1998, Lange et al., 1998) and promotes axon growth through integrin receptors (Pasterkamp et al, 2003).

From our study, one is surprised that such a large variety of semaphorins and related receptors display expression changes after drug treatment. On the other hand, splice variants of semaphorin RNA transcripts also are important for regulating plasticity in neurons (Daoud et al., 1999) and nonfunctional isoforms of semaphorin genes, produced through alternative splicing, may be used as regulators of that gene's activity. Furthermore, neuronal activity alters splice patterns (Daoud et al., 1999) and cocaine administration stimulates this activity. Together this may further complicate the pattern and to some extent explain the large diversity of expression pattern of the axon guidance cues identified in this study.

Eph receptors and related Ephrin ligands display significant changes after drug treatment, but of lower intensity than the semaphorins: The Eph family receptor tyrosine kinases include at least 14 receptors and 8 Ephrin ligands (Zhou, 1998) that guide migrating cells and neuronal growth cones to specific destinations by repulsive mechanisms during development of the nervous system (Cheng et al., 1995, Drescher et al., 1995, Feldheim et al., 1998, Gao et al., 1996, Gao et al., 1998). The ligands and receptors are often expressed in opposing gradients, and the ligand-receptor interaction restricts receptor-rich axons to ligand poor areas. Because Eph receptors and ephrins have complementary expression, bidirectional activation of Eph receptors and ephrin-B occur at interfaces of their expression domains (Mellitzer et al., 1999).

In our study we found complementary up-regulation of Eph and their partner ligands, the Ephrin in the Ventral Tegmental Area and in the Nucleus Accumbens after all drug treatments. The upregulation is very significant, although of lower magnitude than changes observed with semaphorins. Similar complementary expression of EphB1 and Ephrin-B2 has been described in the 
nigrostriatal and mesolimbic pathways in the adult after cocaine treatment (Yue et al., 1999). Dopamine activity regulates developmental expression of EphB1 and Ephrin-B2, whereas cocaine administration produced a significant elevation in Ephrin-B2 expression in the Nucleus Accumbens.

Highest changes after drug treatment are found in the Nucleus Accumbens with EphB4, EphB3 and EphB1 in chronically treated animals. By contrast down regulated in the striatum $(\mathrm{CPu})$ is observed with specific EphA and EphrinA. The nature of the specific neural pathways implicated remains to be clarified in more details.

EphA4 and Ephrin-A3 are both up-regulated in the hippocampus. Murai has shown that expression of and signalling through EphrinA3/EphA4 are critical for spine morphology of CA1 pyramidal neurons in the hippocampus (Murai et al, 2003) and for maintaining a stable and dynamic organization of spines during synaptic remodelling in the adult brain, whereas EphB receptor activation induces modest changes in dendritic spines in CA1. Changes in hippocampal spine density and dimensions occur in several mental disorders, including depression, schizophrenia and addiction.

Another study has shown that EphB1, EphB2, and EphB3 are involved all three, although to varying degrees, in dendritic spine morphogenesis and synapse formation in the hippocampus (Henkemeyer et al, 2003). All these candidates are up regulated in that region in all protocols of drug administration

Drug-induced Expression Changes of axon guidance cues may be related to plasticity and learning in addiction: In drug addiction the value of the drug and drug-related stimuli is enhanced, at the expense of other reinforcers, as a consequence of conditioned learning. The memory of the expected reward results in over activation of the reward and motivation circuits while decreasing the activity in the cognitive control circuit, which contributes to an inability to inhibit the drive to consume the drug (Volkow et al., 2003). Thus conditioned-learned associations and cognitive control is a key process in drug addiction. On the other hand several studies have implied axon guidance cues in synaptic plasticity and learning (Gerlai et al., 2001). EphB2 regulates NMDA-dependent synaptic function and is up regulated in hippocampal pyramidal neurons by stimuli known to induce changes 
in synaptic structure (Henderson et al., 2001). Mice lacking EphB2 have normal hippocampal synapse morphology, but display defects in synaptic plasticity (Grunwald et al, 2001), long-term potentiation (LTP) is impaired, and two forms of synaptic depression are completely extinguished (Gosh, 2002, Grunwald et al., 2001, Henderson et al., 2001). Conditional ablation of Ephrin-B2 and Ephrin-B3, or of EphA4, a high-affinity receptor for these ligands, causes comparable defects in LTP (Grunwald et al., 2004). By contrast, in our study we found up to four-fold induction of EphB2 in the hippocampus, which theoretically should result in improved LTP and thus may be linked to improved cue-mediated conditioned learning as observed in addiction.

On the other hand regulation of neurogenesis is a form of plasticity in the adult rat hippocampus. It has been proposed that drug regulation of neurogenesis in the adult rat hippocampus may be one mechanism by which drug exposure influences hippocampal function (Eisch et al., 2000). Thus drug-induced expression of axon guidance cues, particularly the Ephs and Ephrins, may be part of this process, which may recapitulate expression patterns of cues induced in earlier stages during development. In the adult brain, for example, EphB signalling regulates neural stem cell migration and possibly proliferation and EphB2 and Ephrin-B2, which both are induced by drug treatment in our study, has been shown to substantially increase the number of neural stem cells (Hinamen et al., 2003).

Effect of the drug administration paradigm on gene regulation: In this study, different drug administration paradigms have been used to assess expression changes of plasticity-related cell surface guidance cues. In most cases, chronic treatment or S4 sensitization groups display highest intensities in expression changes compared to other treatments within a given area. Expression changes of a given candidate within a specific brain region do not qualitatively differ from one paradigm to another, whereas only the intensity of the observed change is affected and strongly depends upon the type of treatment, with some exceptions. Therefore, under most circumstances, changes observed with a candidate in one paradigm will be observed also upon other treatments, but at a different intensity: wherever a candidate is up- or down-regulated, the 
regimen does not influence this effect, only its magnitude. Some exceptions are observed, however, but mainly where expression changes of the candidate are of small intensity ( $<2$-fold change).

In several conditions, acute treatment induces strongest changes, while the other treatments have small effects, i.e. for Sema3A and Sema3F in the Nucleus Accumbens, Sema4A and Sema4G in the Ventral Tegmental Area, Sema7A (several regions), and Ephrin-A3 in the Caudate Putamen, etc. It is therefore somewhat surprising that a single dose of drug may induces strong changes, where repeated doses produce lower expression change of the same candidate. This may imply a complex program of compensatory regulation and temporal adaptations of these guidance cues.

In conclusion, we describe differential regulation of a large array of guidance cues in several brain regions in response to cocaine. The involvement of multiple Semaphorins, Neuropilins, Ephs and Ephrins in cocaine action suggests the activation of a complex program of synaptic rearrangements induced by the drug, which may recapitulate the plastic changes occurring during development in terms of mechanisms and of the molecular players involved. Local expression changes of these cues may mediate cytoskeleton rearrangement via signalling and induce synaptic plasticity, through mechanisms similar to synaptic targeting during development (Yue et al, 2002). These cues display a high range of functional characteristics, illustrating the complexity and the variability of neuroadaptations induced in the brain by psychostimulant treatment. Furthermore alternative splicing forms of these molecules have been described in many cases, which affect their binding and signalling properties, further complicating the pattern. The changes observed in this study are consistent with a role in addiction and may contribute to drug-related reinforcing of the mesolimbic circuits. Clearly, important neuroplastic changes occur in the reward- and memory-related brain centers following drug action. Together, these finding help clarifying the molecular and cellular events involved in early stages of drug addiction. The fact that the candidates investigated in this study regulate both axon guidance, during 
development, and postnatal synaptic function emphasizes the varied roles of these cues in regulating cell-cell interaction within the CNS. 


\section{REFERENCES}

Adams RH, Betz H, Puschel AW. (1996) A novel class of murine semaphorins with homology to thrombospondin is differentially expressed during early embryogenesis. Mech Dev., 57, 33-45.

Atwal JK, Singh KK, Tessier-Lavigne M, Miller FD, Kaplan DR. (2003) Semaphorin $3 \mathrm{~F}$ antagonizes neurotrophin-induced phosphatidylinositol 3-kinase and mitogen-activated protein kinase kinase signaling: a mechanism for growth cone collapse. J Neurosci 23, 7602-9.

Bagri A, Tessier-Lavigne M. (2002) Neuropilins as Semaphorin receptors: in vivo functions in neuronal cell migration and axon guidance. Adv Exp Med Biol 515, 13-31.

Bahi A, Boyer F, Kafri T, Dreyer J-L. (2004) CD81-induced Behavioral Changes during Chronic Cocaine Administration. In vivo Gene Delivery with regulatable Lentivirus. Eur J Neurosci 19, 1621-33.

Bardo MT. (1998) Neuropharmacological mechanisms of drug reward: beyond dopamine in the nucleus accumbens. Crit Rev Neurobiol 12, 37-67.

Barnes G, Puranam RS, Luo Y, McNamara JO. (2003) Temporal specific patterns of semaphorin gene expression in rat brain after kainic acid-induced status epilepticus. Hippocampus 13, 1-20.

Battaglia AA, Sehayek K, Grist J, McMahon SB, Gavazzi I. (2003) EphB receptors and ephrinBs regulate spinal sensory connectivity and modulate pain processing in the adult rat. Nat. Neurosci 6, 339-40.

Beitner-Johnson D, Guitart X, Nestler EJ. (1992). Neurofilament proteins and the mesolimbic dopamine system: common regulation by chronic morphine and chronic cocaine in the rat ventral tegmental area. J Neurosci 12, 2165-76. 
Berhow MT, Russell DS, Terwilliger RZ, Beitner-Johnson D, Self DW, Lindsay RM, Nestler EJ. (1995) Influence of neurotrophic factors on morphine- and cocaine-induced biochemical changes in the mesolimbic dopamine system. Neuroscience 68, 969-79.

Berhow MT, Hiroi N, Kobierski LA, Hyman SE, Nestler EJ. (1996) Influence of cocaine on the JAK-STAT pathway in the mesolimbic dopamine system. J Neurosci 16, 8019-26.

Berke JD, Paletzki RF, Aronson GJ, Hyman SE, Gerfen CR. (1998) A complex program of striatal gene expression induced by dopaminergic stimulation. J Neurosci 18, 5301-10.

Brenz-Verca MS, Widmer DAJ, Wagner GC, Dreyer JL (2001) Cocaine-induced Expression of the Tetraspanin CD81 and its Relation to Hypothalamic Function. Mol Cell Neurosciences 17, 303-316.

Cheng H-J, Nakamoto M, Beregmann AD, Flanagan JG. (1995). Complementary gradients in expression and binding of ELF-1 and Mek4 in development of the topographic retinotectal map. Cell 82, 371-381.

Chao J, Nestler EJ. (2004) Molecular Neurobiology of Drug Addiction. Ann. Rev. Med., 55, 113-32.

Couceyro P, Shoaib M, McCoy M, Goldberg SR, Kuhar MJ. (1997a) Cocaine self-administration alters brain $\mathrm{NADH}$ dehydrogenase mRNA levels. Neuroreport 8, 2437-41.

Daoud R, Da Penha Berzaghi M, Siedler F, Hubener M, Stamm S. (1999) Activity-dependent regulation of alternative splicing patterns in the rat brain. Eur J Neurosci 11, 788-802.

DeWit J, Verhaagen J. (2003) Role of Semaphorins in the Adult Nervous System. Progr Neurobiol 71, 249-267. 
Drescher U, Kremoser C, Handwerker C, Loschinger J, Noda M, Bonhoeffer F. (1995). In vitro guidance of retinal ganglion axons by RAGS, a $25 \mathrm{kDA}$ tectal protein related to ligands for Eph receptor tyrosine kinases. Cell 82, 359-370.

Eckhardt F, Meyerhans A. (1998) Cloning and expression pattern of a murine semaphorin homologous to H-sema IV. Neuroreport 9, 3975-9.

Eisch AJ, Barrot M, Schad MA, Self DW, Nestler EJ (2000) Opiates inhibit neurogenesis in the adult rat hippocampus. Proc. Natl Acad. Sci USA. 97, 7579-7584.

Feldheim DA, Vanderhaegen P, Hansen MJ, Frisen J, Lu Q, Barbacid M, Flanagan JG. (1998) Topographic guidance labels in a sensory projection to forebrain. Neuron 21, 1303-1313.

Flanagan J, Vanderhagen P. (1998). The Ephrins and Eph receptors in neural development. Annu. Rev. Neurosci 21, 309-345.

Gao P-P, Zhang J-H, Yokoyama M, Racey B, Dreyfus CF, Black IB, Zhou R. (1996). Regulation of topographic projection in the brain: Elf-1 in the hippocampalseptal system. Proc Natl Acad Sci USA 93,11161-11166.

Gao P-P, Yue Y, Zhang J-H, Cerretti DP, Levitt P, Zhou R. (1998). Regulation of thalmic neurite outgrowth by the Eph ligand ephrinA5: implications in the development of thalmocortical projections. Proc Natl Acad Sci USA 95,5329-5334.

Gerlai R. (2001) Eph receptors and neural plasticity. Nat Rev Neurosci 2,205-9.

Ghasemzadeh MB, Nelson LC, Lu XY Kalivas PW. (1999) Neuroadaptations in ionotropic and metabotropic glutamate receptor mRNA produced by cocaine treatment. J Neurochem 72, 157-65. 
Godenschwege TA, Hu H, Shan-Crofts X, Goodman CS, Murphey RK. (2002) Bi-directional signaling by Semaphorin 1a during central synapse formation in Drosophila. Nat Neurosci 5, 1294-301.

Goldberg JL, Vargas ME, Wang JT, Mandemakers W, Oster SF, Sretavan DW, Barres BA. (2004) An oligodendrocyte lineagespecific semaphorin, Sema5A, inhibits axon growth by retinal ganglion cells.J Neurosci. 24, 4989-99.

Good PF, Chu C, Hsu A, Perl DP, Wen X, Burstein DE, Kohtz DS. (2002) A role for Semaphorin 3A signaling in the degeneration of hippocampal neurons during Alzheimer's disease. Soc. Neurosc. Abstr. 328, 8 .

Gosh A (2002) Learning more about NMDA Receptor Regulation. Science 295, 449-50.

Goshima Y, Ito T, Sasaki Y, Nakamura F. (2002) Semaphorins as signals for cell repulsion and invasion. J Clin. Invest 109, 993-998.

Grunwald IC, Korte M, Wolfer D, Wilkinson GA, Unsicker K, Lipp HP, Bonhoeffer T, Klein R. (2001) Kinase-independent requirement of EphB2 receptors in hippocampal synaptic plasticity. Neuron 32,102740.

Grunwald IC, Korte M, Adelmann G, Plueck A, Kullander K, Adams RH, Frotscher M, Bonhoeffer T, Klein R. (2004) Hippocampal plasticity requires postsynaptic ephrinBs. Nat Neurosci 7, 33-40.

Halladay AK, Yue Y, Michna L, Widmer DAJ, Wagner GC, Zhou R. (2000) Regulation of EphB1 expression by dopamine signaling. Molecular Brain Research 85, 171-178.

Henderson JT, Georgiou J, Jia ZP, Robertson J, Elow S, Roder JC, Pawson T. (2001) The receptor tyrosine kinase EphB2 regulates NMDA-dependent postnatal synaptic plasticity. Neuron 32, 10411056. 
Henkemeyer M, Itkis OS, Ngo M, Hickmott PW, Ethell IM. (2003). Multiple EphB receptor tyrosine kinases shape dendritic spines in the hippocampus. J Cell Biol. 163,1313-26.

Hinamen JP, Nikolov DB (2003) Molecules in Focus. Eph Receptors and Ephrins. Int J. Biochem Cell Biol 35, 130-134.

Inagaki S, Furuyama T, Iwahashi Y. (1995) Identification of a member of mouse semaphorin family. FEBS Lett. 370, 269-72.

Ip NY, Yancopoulos GD (1996) The neurotrophins and CNTF: two families of collaborative neurotrophic factors. Annu Rev Neurosci 19, 491-515.

Kacharmina JE, Crino PB, Eberwine J. (1999) Preparation of cDNA from single cells and subcellular regions. Methods Enzymol. 303: 3-18.

Knöll B, Isenmann S, Kilic E, Walkenhorst J, Engels S, Wehninger J, Bähr M Drescher U. (2001) Graded expression patterns of ephrin-As in the superior colliculus after lesion of the adult mouse optic nerve. Mechanisms of Development 106, 119-27.

Lange C, Liehr T, Goen M, Gebhart E, Fleckenstein B, Ensser A. (1998) New eukaryotic semaphorins with close homology to semaphorins of DNA viruses. Genomics, 51, 340-50.

Marin O, Yaron A, Bagri A, Tessier-Lavigne M, Rubenstein JL. (2001) Sorting of striatal and cortical interneurons regulated by semaphorinneuropilin interactions. Science 293, 872-5.

McClung CA, Nestler EJ. (2003) Regulation of gene expression and cocaine reward by CREB and DeltaFosB. Nature Neuroscience 6, 120815.

Mellitzer G, Xu Q, Wilkinson DG (1999). Eph receptors and ephrins restrict cell intermingling and communication. Nature 400, 77-81. 
Messersmith EK, Leonardo ED, Shatz CJ, Tessier-Lavigne M, Goodman CS, Kolodkin AL. (1995) Semaphorin III can function as a selective chemorepellent to pattern sensory projections in the spinal cord. Neuron, 14, 949-959.

Michna L, Brenz Verca MS, Widmer DAJ, Chen SL, Rogrove J, Zhou R, Tsitsikov E, Miescher GC, J-L. Dreyer JL, Wagner GC (2001) Altered Sensitivity of CD81-deficient mice to neurobehavioral effects of cocaine. Mol Brain Res 90, 68-74.

Moratalla R, Vallejo M, Elibol B, Graybiel, AM. (1996) D1-class dopamine receptors influence cocaine-induced persistent expression of Fos-related proteins in striatum. Neuroreport 8, 1-5.

Moratalla R, Vickers EA, Robertson HA, Cochran BH, Graybiel AM. (1993) Coordinate expression of c-fos and jun B is induced in the rat striatum by cocaine. J Neurosci 13, 423-33.

Mühlbauer M, Allard B, Bosserhoff AK, Kiessling S, Herfarth H, Rogler G, Schölmerich J, Jobin C, Hellerbrand C. (2004) Differential Effects of Deoxycholic Acid and Taurodeoxycholic Acid on NF\{kappa\}B Signal Transduction and IL-8 Gene Expression in Colonic Epithelial Cells. Am J Physiol Gastrointest Liver Physiol. 286, G1000-8.

Murai KK, Nguyen LN, Irie F, Yamaguchi Y, Pascale EB. (2003) Control of hippocampal dendrite spine morphology through ephrinA3/EphA4 signaling. Nature Neuroscience 6, 153-160.

Nestler EJ. (1997) Molecular mechanisms of opiate and cocaine addiction. Curr Opin Neurobiol 7, 713-9.

Nestler EJ. (2000) Genes and addiction. Nature genetics 26, 277-281. 
Nestler EJ, Kelz MB, Chen J. (1999). DeltaFosB: a molecular mediator of long-term neural and behavioral plasticity. Brain Res 835, 10-7.

Nestler EJ, Terwilliger RZ, Walker JR, Sevarino KA, Duman RS. (1990). Chronic cocaine treatment decreases levels of the $G$ protein subunits Gi alpha and Go alpha in discrete regions of rat brain. $J$ Neurochem 55, 1079-82.

Nestler EJ, Berhow MT, Brodkin ES. (1996) Molecular mechanisms of drug addiction: adaptations in signal transduction pathways. Mol Psychiatry 1, 190-9.

Nestler EJ, Aghajanian GK. (1997) Molecular and cellular basis of addiction. Science 278, 58-63.

Neugebauer KM, Emmett CJ, Venstrom KA, Reichardt LF. (1991) Vitronectin and thrombospondin promote retinal neurite outgrowth: developmental regulation and role of integrins. Neuron. 6, 345-58.

Osterfield M, Kirschner MW, Flanagan JG. (2003) Graded positional information: interpretation for both fate and guidance. Cell 113, 425-8.

Pasquale E. (2000) Neurobiology. Turning attraction into repulsion. Science 289,1308-10.

Pasterkamp RJ, DeWinter F, Holtmaat AJ, Verhaagen J. (1998) Evidence for a role of the chemorepellent semaphorin III and its receptor neuropilin-1 in the regeneration of primary olfactory axons. J Neurosci 18, 9962-76.

Pasterkamp RJ, Peschon JJ, Spriggs MK, Kolodkin AL. (2003) Semaphorin 7A promotes axon outgrowth through integrins and MAPKs. Nature, 424, 398-405.

Püschel AW. (2002) The function of neuropilin/plexin complexes. Adv Exp Med Biol 515,71-80. 
Puschel AW, Adams RH, Betz H. (1996) The sensory innervation of the mouse spinal cord may be patterned by differential expression of and differential responsiveness to semaphorins. Mol Cell Neurosci 7, 419-31.

Qu X, Wei H, Zhai Y, Que H, Chen Q, Tang F, Wu Y, Xing G, Zhu Y, Liu S, Fan M, He F. (2002) Identification, characterization, and functional study of the two novel human members of the semaphorin gene family. J Biol Chem 277, 35574-85.

Robinson TE, Berridge KC. (1993) The neural basis of drug craving: an incentive-sensitization theory of addiction. Brain Res Brain Res Rev 18, 247-91.

Sato Y, Takahashi H. (1998) Molecular cloning and expression of murine homologue of semaphorin K1 gene. Biochim Biophys Acta 1443, 419-22.

Schultz W. (1998). Predictive reward signal of dopamine neurons. J Neurophysiol 80, 1-27.

Semaphorin Nomenclature Committee. (1999) Unified nomenclature for the semaphorins/collapsins. Cell, 97, 551-2.

Sheng M. (2001) Molecular organization of the postsynaptic specialization. Proc. Natl. Acad. Sci. USA, 98, 7058-7061.

Simmons, AD, Püschel AW, McPherson JD, Overhauser J, Lovett M. (1998). Molecular cloning and mapping of human semaphorin F from the Cri-du- chat candidate interval. Biochem Biophys Res Commun 242, 685-91.

Skaliora I, Singer W, Betz H, Püschel AW. (1998). Differential patterns of semaphorin expression in the developing rat brain. Eur J Neurosci 10, 1215-29. 
Sklair-Tavron L, Shi WX, Lane SB, Harris HW, Bunney BS, Nestler EJ. (1996) Chronic morphine induces visible changes in the morphology of mesolimbic dopamine neurons. Proc Natl Acad Sci USA 93,11202-7.

Steup A, Ninnemann O, Savaskan NE, Nitsch R, Püschel AW, Skutella T. (1999) Semaphorin D acts as a repulsive factor for entorhinal and hippocampal neurons. Eur J Neurosci 11, 729-734.

Sieber B-A, Kuzmin A, Canals JM, Danielsson A, Paratcha G, Arenas D, Alberch J, Ovegren S, Ibanez CF. (2004) Disruption of EphA/ephrin-A signaling in the nigrostriatal system reduces dopaminergic innervation and dissociates behavioral responses to amphetamine and cocaine. Mol Cell Neurosci. 26, 418-428.

Tamagnone L, Artigiani S, Chen H, He Z, Ming GI, Song H, Chedotal A, Winberg ML, Goodman CS, Poo M, Tessier-Lavigne M, Comoglio PM. (1999). Plexins are a large family of receptors for transmembrane, secreted, and GPI-anchored semaphorins in vertebrates. Cell 99, 71-80.

Volkow ND, Fowler JS, Wang GJ. (2003) The addicted human brain: insights from imaging studies. J Clin Invest 111, 1444-1451.

Wang, JQ, McGinty JF. (1997) The full D1 dopamine receptor agonist SKF-82958 induces neuropeptide mRNA in the normosensitive striatum of rats: regulation of D1/D2 interactions by muscarinic receptors. J Pharmacol Exp Ther 281, 972-82.

Widmer DAJ (2000) Cocaine-Induced Expression of Axon Guidance Molecules. Dissertation. Graduate School Rutgers State University, NJ.

Williams-Hogarth LC, Puche AC, Torrey C, Cai X, Song I, Kolodkin AL, Shipley MT, Ronnett GV. (2000). Expression of semaphorins in developing and regenerating olfactory epithelium. J Comp Neurol 42, $565-78$. 
Willson CA, Irizarry-Ramirez M, Gaskins HE, Cruz-Orengo L, Figueroa JD, Whittemore SR, Miranda JD. (2002) Upregulation of EphA receptor expression in the injured adult rat spinal cord. Cell Transplant 11, 229-39.

Xu F, Gainetdinov RR, Wetsel WC, Jones SR, Bohn LM, Miller GW, Wang YM, Caron MG. (2000) Mice lacking the norepinephrine transporter are supersensitive to psychostimulants. Nat Neurosci 3, $465-71$.

Xu M, Hu XT, Cooper DC, White FJ, Tonegawa S. (1996) A genetic approach to study mechanisms of cocaine action. Ann N Y Acad Sci 801,51-63.

Xu X, Ng S, Wu ZL, Nguyen D, Homburger S, Seidel-Dugan C, Ebens A, Luo Y. (1998) Human semaphorin K1 is glycosylphosphatidylinositol-linked and defines a new subfamily of viral-related semaphorins. J. Biol. Chem. 273, 22328-22434.

Yu TW, Bargmann CI. (2001) Dynamic Regulation of Axon Guidance. Nature Neuroscience, 4, 1169-1176.

Yue Y, Chen ZY, Gale NW, Flynn JB, Hu TJ, Yue X, Cooper M, Crockett DJ, Yancopoulos GD, Tessarollo L, Zhou R (2002) Mistargeting hippocampal axons by expression of a truncated Eph receptor. Proc Natl Acad Sci USA, 99, 10777-82.

Yue Y, Widmer DAJ, Halladay AK, Cerretti DP, Wagner GC, Dreyer J-L, Zhou R. (1999) Specification of distinct dopaminergic neural pathways: role of the Eph family receptor EphB1 and ligand EphrinB2. J Neurosci 19, 2090-2101.

Zhou R. (1998). The Eph family receptors and ligands. Pharmacol Ther 77, 151-181. 


\section{Figure Legends}

\section{Figure 1. Protocols of Drug administration.}

A) Acute Treatment. Animals $(n=6)$ are injected a single dose of cocaine $(15 \mathrm{mg} / \mathrm{kg})$ and sacrificed $24 \mathrm{~h}$ after injection.

B) Binge Treatment. Animals $(n=6)$ receive four injections of high dose cocaine $(30 \mathrm{mg} / \mathrm{kg})$ and are sacrificed $24 \mathrm{~h}$ after the last injection.

C) Chronic Treatment. Animals $(n=6)$ receive a single dose of cocaine $(15 \mathrm{mg} / \mathrm{kg})$ every day over 15 days and are sacrificed $24 \mathrm{~h}$ after the last injection. In each treatment (acute, binge or chronic), control animals were injected saline. In each cases aRNA samples of brain regions from controls (reverse transcribed as Cy3-dCTP) and from treated animals (reverse-transcribed as Cy5-dCTP) were prepared, hybridized on microarrays and the ratios measured.

D) Sensitization Treatment. Four groups of animals $(n=6)$ are used. Each group receives initially five daily injections of either saline (groups S1 and S2) or cocaine (15 mg/kg, groups S3 and S4).

Short withdrawal groups: three days after the last injection, groups S1 and S3 are challenged with a single dose of either saline (group S1) or cocaine $(15 \mathrm{mg} / \mathrm{kg}$, group S3) and sacrificed $24 \mathrm{~h}$ after the injection.

Long withdrawal groups: fourteen days after the last injection, groups S2 and S4 are challenged a single dose of either saline (group S2) or cocaine (15 mg/kg, group S4) and sacrificed $24 \mathrm{~h}$ after the last injection.

Groups S1 and S2 are animals sensitized with saline and challenged after a short withdrawal period (3 days, group S1) or a long withdrawal period (14 days, group S2). Groups S3 and S4 are animals sensitized with cocaine and challenged after a short withdrawal period (3 days, group S3) or a long withdrawal period (14 days, group S4). aRNA samples of brain regions from controls (challenged with saline, reverse transcribed as Cy3-dCTP) and from treated samples (challenged with cocaine, reverse-transcribed as Cy5-dCTP) were prepared, hybridized on microarrays and the ratios measured. 
Figure 2. Expression Patterns of Controls and Semaphorins.

Upper panel: Expression changes of the 10 positive control genes are represented as ratios of cocaine-treated versus saline-treated samples from tissues of the four regions under investigation, each at the seven different conditions of drug administration.

Lower panel: Expression changes of the Semaphorins, in the same regions and conditions as in the upper panel.

Microarrays were scanned with a scanning laser microscope (Methods section). Each bar represents the means of ratios from 8 hybridization spots per gene from three independent tissue samples for a single treatment paradigm, with standard deviation (see Material and Methods section for details). Standard deviation was $<8.5 \%$ in all cases. Color codes: as indicated in the figure, corresponding each to different drug administration protocols.

For all control genes no significant change of expression is observed under any condition and the ratio between samples from cocainetreated and saline-treated tissues is almost 1.0.

E2a: Transcription factor E2 LDH-A : Lactate dehydrogenase A, HSP70: Heat Shock Protein 70, GP62: Nuclear Pore Glycoprotein 62 ,

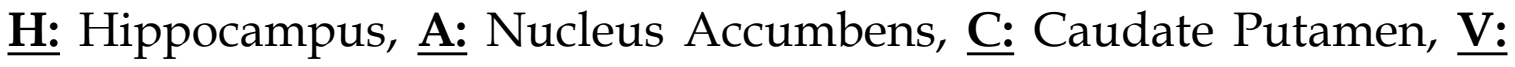
Ventral Tegmentum Area. 
Figure 3. Expression Patterns of Neuropilins, Eph's and Ephrins.

Upper panel: Expression changes of the Neuropilins, NP-1 and NP-2. Middle panel: Expression changes of the Eph-A and their corresponding ligands, the Ephrin-A.

Lower panel: Expression changes of the Eph-B and their corresponding ligands, the Ephrin-B.

Same representations as in figure 2, in the same regions and conditions of drug administration, with standard deviations. The same color codes in figure 2 (as indicated) are used for representing the different treatment conditions. Each bar represents the means of ratios (sample from cocaine-treated tissue versus sample from saline treated tissue) from 8 hybridization spots per gene from three independent tissue samples for a single treatment paradigm, with standard deviation. Standard deviation was $<8.5 \%$ in all cases.

NP1: Neuropilin1, NP2: Neuropilin2.

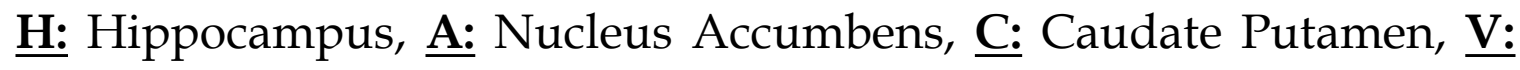
Ventral Tegmentum Area.

Figure 4. mRNA Quantification of Candidate Transcripts: Comparison of Quantitative Real-Time PCR and Microarray.

QRT-PCR: quantification of gene transcripts by means of quantitative real-time PCR. Microarray: quantification of gene transcripts on microarray (see figures 2 and 3 and Material and Methods).

Colour codes correspond to the different protocols (as indicated

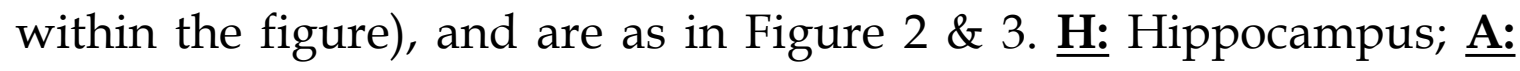
Nucleus Accumbens; C: Caudate Putamen; V: Ventral Tegmental Area. Standard deviation for RT-PCR was $<4 \%$, and for microarrays $<8.5 \%$, in all cases.

For qRT-PCR, the relative abundance of candidate transcripts in total RNA from different tissue samples and from different protocols was determined by real-time RT-PCR and expressed relative to GAPDH for replicate determinations (as described in the "Materials and Methods"). After normalization, the ratios between samples from cocaine-treated and saline-treated tissues were calculated. 
Fig. 1

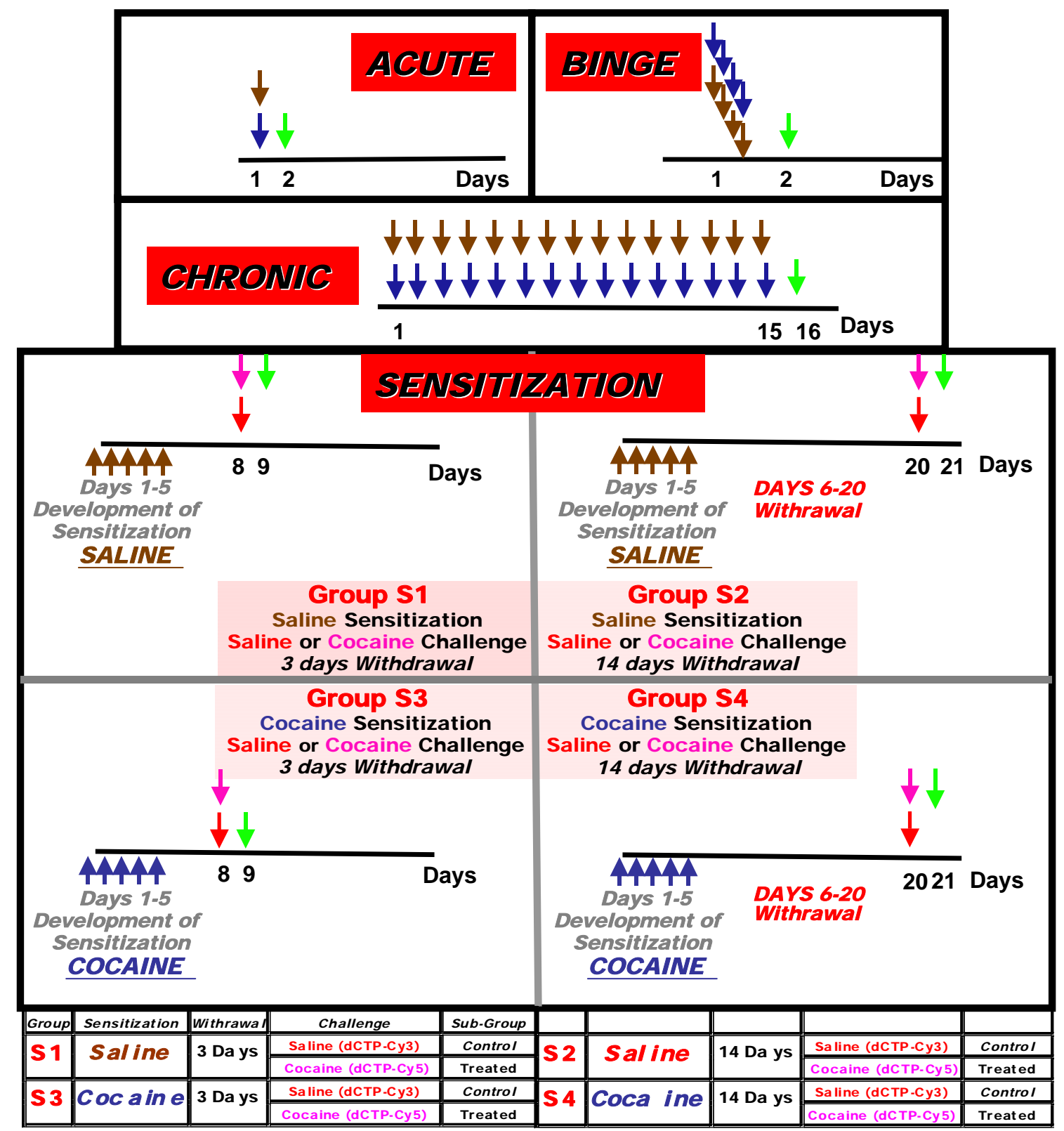

Saline Injection

Cocaine Injection

Saline Challenge

Cocaine Challenge

\section{Sacrifice - Dissection}


Fig. 2

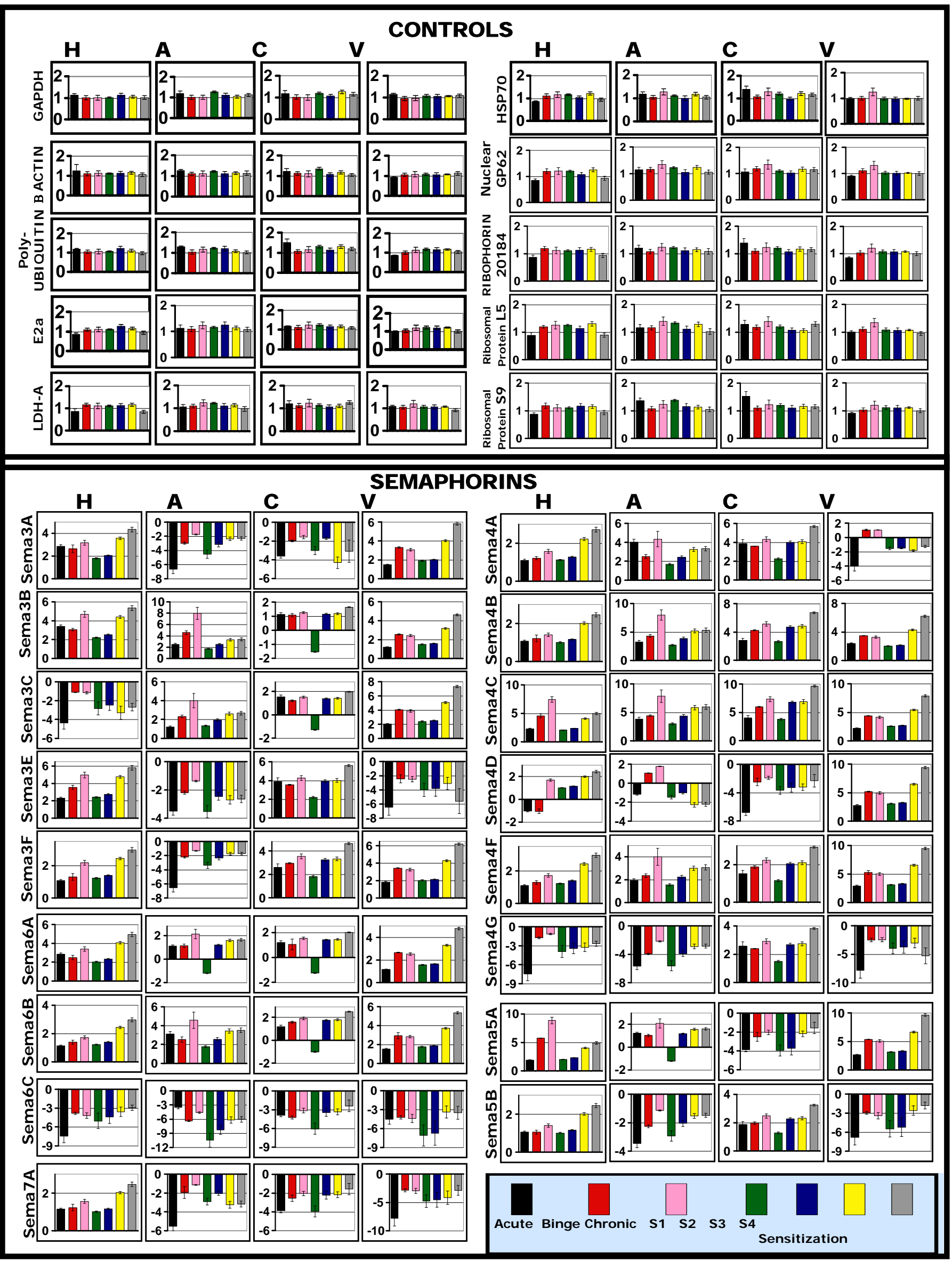


Fig. 4

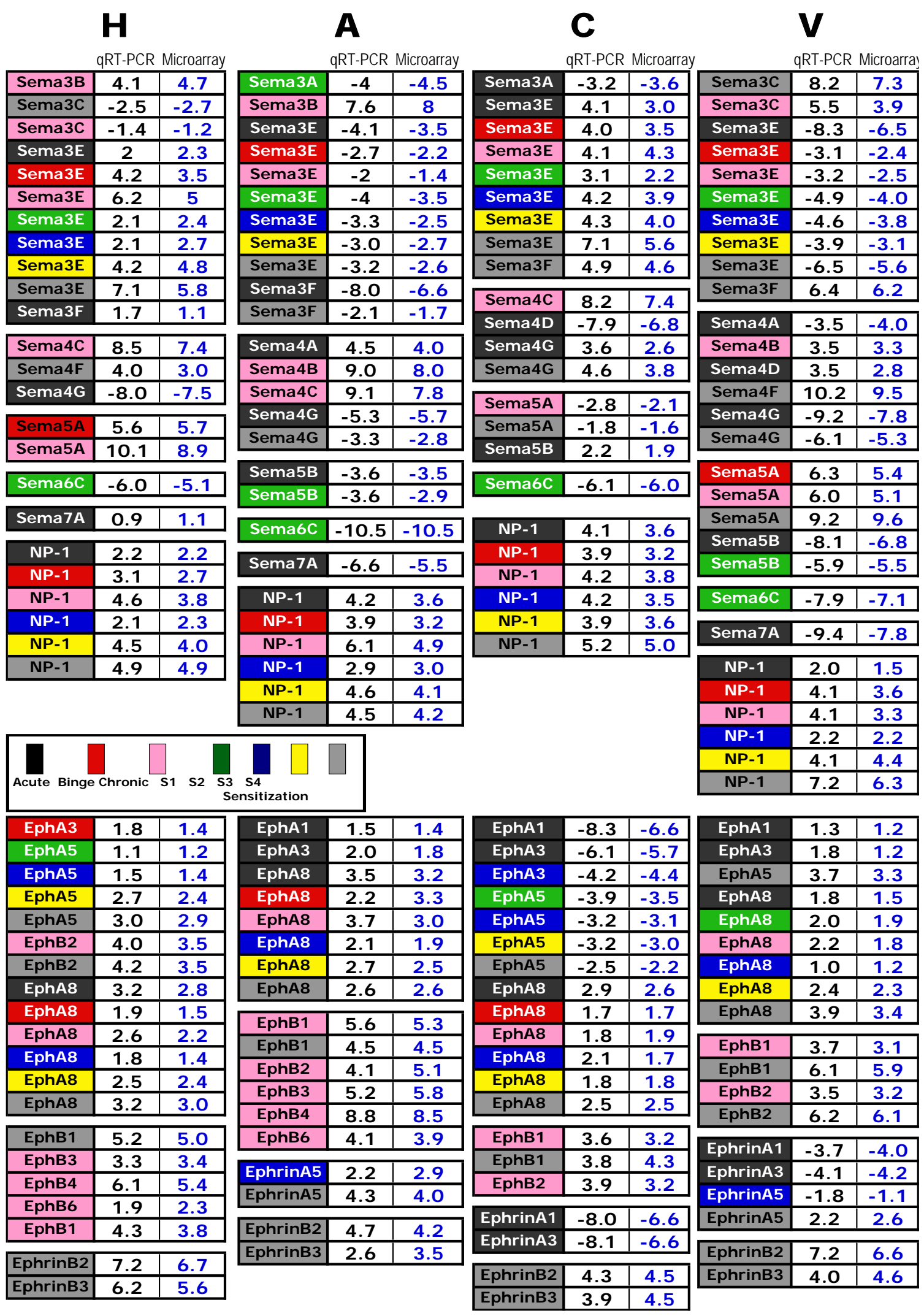


Table 1. Gene candidates and Oligonucleotides.

Gene candidates, species and Gene ID (NCBI) are listed. Oligonucleotides for the different candidates were designed and checked ("Materials and Methods“). Oligonucleotides synthesized with 5'-amino modification, were arrayed onto QMT Aldehyde Slides with an OmniGrid Accent ${ }^{\mathrm{TM}}$ Microarrayer. aRNA samples (from samples of cocaine-treated and of saline-treated tissues) were reverse-transcribed in the presence of Cy3-dCTP (samples from salinetreated tissues) or Cy5-dCTP (samples from cocaine-treated tissues) and hybridized. See Material and Methods for details.

\begin{tabular}{|c|c|c|c|}
\hline Name & Species & Gene_Id & Oligo Sequence \\
\hline Sema3A & Rat & X95286 & GAAGAAGGATTCAGGCAATTACCTGTGTCACGCCGTGGAGCACGGTTTCATGCAAACTCTTCTTAAGGTG \\
\hline Sema3B & Mouse & $\mathrm{X} 85990$ & CCAGCACCCTATGCTCTGGAGACTCTTCTCACTCTGTGCTGCTGGAGAAGAAGGTGTTGGGTGTGGAGAG \\
\hline Sema3C & Mouse & $x 85994$ & CAATGGAAATCTCATCCAAAAAGCAACAGTTGTACGTGAGCTCCAATGAGGGGGTTTCCCAAGTCTCTCT \\
\hline Sema3E & Mouse & $\overline{Z 80941}$ & CTTAAGCGGTATGTCTCAGGGGACAAAACCGTGGTACAAGGAATTCTTGCAGCTGATTGGCTACAGCAAC \\
\hline Sema3F & Mouse & AF080090 & TCAATTCCAATGCAAACAAGAATGCCGTAGAGTCTGTGCAGTACGGAGTGGCCGGCAGCGCAGCTTTCCT \\
\hline Sema4A & Mouse & $\mathrm{X} 85991$ & GTTTGGACAGATTGTTATTATTGTCTCTGCCCTGGCTAGAATGGGGGCATAATCTGAGCCTTGTTCCCTT \\
\hline Sema4B & Mouse & $\underline{\underline{X 85992}}$ & CAAGAATTCCTCATACAAGGCCCGGTTTCTTGTGCCAGGTAAGCCATGTAAACAAGTCCAGATCCAACCA \\
\hline Sema4C & Mouse & $\underline{\mathrm{S} 79463}$ & ACTTTCCTGTCTCTATCACGTCTTCCCTTGGCCTGGGGTCCTCCTGGTTGAGTCTTTGGAGCTATGAAGG \\
\hline Sema4D & Mouse & U69535 & CAAATGTTTCCAAAAGTCCAACCTAGCCCGGGTGGTATGGAAGTTCCAGAATGGCGAGTTGAAGGCCGCA \\
\hline Sema4F & Rat & $\mathrm{AB} 002563$ & CTAACCTAGCAGCATTGATCGTTCATTGTAAAGTGGGGATATACCTACCTCAGGGTTGCTGCAAGGATCA \\
\hline Sema4G & Mouse & AF134918 & AGATTTCCCTTCCCATTTATCGGTCCTCACTGAACTAGGACAAGTGGCCAACACTGCACTCAATGAGCCA \\
\hline Sema5A & Mouse & $\underline{\underline{X 97817}}$ & GCTCTTATACTTTGGGCTCGTTGTAAACTCGCTGCTCCTCAAACCGTGCTCCATGGCTGCCCCATATTTC \\
\hline Sema5B & Mouse & $\mathrm{x} 978181$ & GTAGAACCACTTTGGTTTACCCTCTGCACTGGGCCAAGAACTTGCTGCCTAGCCAGTAAGGGTCCCATCT \\
\hline Sema6A & Mouse & AF030430 & GGCTGCCACCCTGGAGTATAAGACCATCAAAGAGCACCTGAGTAGCGAGAGTTCACCCTATGTTCTGAAG \\
\hline Sema6B & Rat & AB000776 & GAACCTACTTCTAAAGGGCTTGTGGGGGGTTTTTGGGAGGGTGGAAGTGGGCAGACACCCCTGTAAATACA \\
\hline Sema7A & Mouse & AB017532 & TATTTTTTCGAAATCTCACACTTGACTTCATGCAGTGATGCACCTGGCCTGAGAGCCCATCAGCCTGGCA \\
\hline Sema6C & Rat & AB000817 & GCCTTCCCGGACTCCAAGAGTCTCCCGGGGTCCCCTCTCGCCTCGGTTTATTTATTGACTGTCTTTCCCC \\
\hline EphA1 & Mouse & $\underline{\mathrm{U} 18084}$ & GGAATAGCTCTGCTGATCGGGATTTATGTCTTCCGTTCAAGGAGAGGCCAGAGACAGAGACAGCAGAGGC \\
\hline EphA2 & Mouse & $\mathrm{X78339}$ & AGGTCAACACAGTGGGGATTCCTATCTGAGTCCATTGGG \\
\hline EphA3 & RAT & $\underline{\mathrm{U} 69278}$ & TGGACCAAAGCAATGTCGATATTGCTACGTTCCACACAACAGGTGATTGGCTTAACGGTATGAGGACAGC \\
\hline EphA4 & Mouse & $\underline{X 65138}$ & GGCCCATTCATGCTGCCTCTTCAATGGCCAGGACACCTGGTGGATTTTTATGACATAGGGGGGGTTAGAA \\
\hline EphA5 & Rat & X78689 & GTTTGAAGACACTGGTGAACGCGTCAAGCAGGGTATCTACTTTGTTGGCAGAACATGGATCTTTGGGGTC \\
\hline EphA7 & Rat & U21954 & GACCAGAGCACTCCCGACTTCACTGCCTTCTGTTCAGTGGGAGAGTGGTTGCAGGCTATTAAAATGGAGA \\
\hline EphA8 & Rat & $\mathrm{x} 59290$ & GGTACTCCTCCCTTGGCATGGTGCTTCACATGAACGCCCAGGATGTTCGTGCCCTCGGCATCACCCTCAT \\
\hline EphB1 & Rat & $\overline{\underline{X 13411}}$ & TTTCTCGGCCATGGAAGTGTGTAGAAGCCGTGGGAAACCAAACGCGTAATGATTGACGATAAAGACAGAG \\
\hline EphB2 & Mouse & $\underline{\mathrm{L} 25890}$ & TTTGCCAACGCCGGCTTCACCTCTTTCGACGTTGTATCTCAGATGATGATGGAGGACATTCTCCGCGTTG \\
\hline EphB3 & Mouse & $\underline{Z} 49086$ & CCCAGGAAGTGTGCCCCAAACCTCTTCATATTGAAGATGGATTAGAAGAGGGGGTGATGTCCCCTCCCCA \\
\hline EphB4 & Mouse & $\underline{\underline{Z 49085}}$ & GACAGTTCCCCGGAATTCCGGCAAGGATGCGCCGCTATATTAAGAATCCTCGAATTGTGCTATTGGATTC \\
\hline EphB6 & Mouse & $\underline{\underline{\mathrm{L} 77867}}$ & TCCCCAGGCCTGGCTTTCAGCCATTGGACTAGAGTGCTACCAGGACAACTTCTCCAAGTTTGGTCTTTCC \\
\hline Ephrin A1 & Rat & D38056 & TGCTGCAAACTCAGTGAAGGTATTTGCTTGCCCTGGCTTACGGATTGGCACGGGACTAAGGGGCAGGGTT \\
\hline EphrinA2 & Mouse & U14941 & ACTCGCTTTCACCAGGCCACCAGGGCCATCCAGTGTTGTTTAATTACAGTCGGAAAGACTTAAGGTTTTT \\
\hline EphrinA3 & Mouse & U90666 & TGGACATTATTTGTCCGCACTACAACAGCTCAGGGCCTGGCGGCGGGGCGGACAGGTACGTGCTGTACAT \\
\hline EphrinA4 & Mouse & U90663 & TCCAGCGCTGGAATTGCTCGATGCCTTTTGCCCCTTTCAGCCCTGTTCGATTCTCAGAAAAGATTCAGCG \\
\hline EphrinA5 & RAT & U69279 & CAAAGGGTTCAAGAGATGGGAATGTAACCGGCCTCACTCTCCAAACGGACCGCTGAAGTTCTCGGAGAAA \\
\hline EphrinB1 & Rat & $\underline{\underline{0} 07560}$ & GCTCTCTTAACCCTAAGTTCCTAAGTGGGAAGGGCTTGGTGATCTACCCGAAGATTGGAGATAAGCTGGA \\
\hline EphrinB2 & Mouse & $\underline{\underline{U 16819}}$ & AGAGGTACTGGAAATAAAAAGCGCAGCGCAGAGCTGTGGGAGAGTCCGTCTGCTTTGGGAGATGTTTTAA \\
\hline EphrinB3 & Mouse & AF025288 & TCCTCTCCTAGTTATGAGTTCTACAAACTGTACCTGGTAGAGGGTGCCCAGGGTCGGCGTTGTGAGGCAC \\
\hline Neuropilin1 & Mouse & D50086 & CTGTGGTGGATTCTTCTCGGAAACTGCAAAATCCAAGATGCTGGCACTAGGCGTTATTCAGTGGGCCCTT \\
\hline Neuropilin2 & Rat & AF016297 & ACAAGGTCAAGATCAATCACCAGAAGTGCTGCTCGGAGGCATGACCGATTGTGTCTGAATCGCTTCTGGC \\
\hline
\end{tabular}


Table 2. Primer sets designed for quantitative RT-PCR.

See Material and Methods.

\begin{tabular}{|c|c|c|}
\cline { 2 - 3 } \multicolumn{1}{c|}{} & Forward Primer & Reverse Primer \\
\hline GAPDH & ATGACTCTACCCACGGCAAG & CATACTCAGCACCAGCATCAC \\
\hline ק-Actin & AGCCATGTACGTAGCCATCC & CTCTCAGCTGTGGTGGTGAA \\
\hline HSP-70 & CCAGCTACGTGGCCTTCAC & GCTTCATGTCCGACTGCAC \\
\hline GP62 & TCTCAGCTCCAGCGACAAC & GCAGTAGTAGTGGTGGTGGTAG \\
\hline LDHA & ACTCTAACACGCTGGCTGAG & CACCCGCACCCTGATACAG \\
\hline Sema3A & GGCTCCTGCTTCGTAGTCTG & GCCATCTCCATCGTCATCTT \\
\hline Sema4F & TTATGCTTGCGAGTGTCAGG & GAGGAGAGTGAGGGATGCTG \\
\hline Sema7A & GCTCCATTGCAGAAGGTTTC & GTTGAGCCTCACGGAGGTAG \\
\hline Neuropilin1 & GGCACCAAGGAGACCACTG & CATCCACAGCAATTCACCAAG \\
\hline EphA3 & GCTGGCAGAAAGACAGGAAC & ACCGTTAAGCCAATCACCTG \\
\hline Sema6B & GCTTATGCAGAATGGCTGGAC & GCGTGTGGGTGTGTTGTG \\
\hline Sema6C & TCAGCCTCCCGATCCATCC & ACAAGCACAGGACACCAAGAG \\
\hline Sema5A & GGACCCCTGTCAACATCTCTG & CCTCTGTCTTCCTACTTCCAGC \\
\hline EphA5 & GCAGACCTGGGTTCTTCAAAG & CATTGTGGGCGGATCAGATTC \\
\hline EphB1 & CCAGTTTGACCATCCCAACATC & GTCTAAAGCGCCATTCTCCATG \\
\hline EphrinA1 & CCTCTCTTGGGTCTGTGCTG & TCCTCGTAATGTGGGCAGATG \\
\hline EphrinB1 & CAAGCTCCGCAAACGACATC & TGTTCTCTGTAGTCCGTAAGGG \\
\hline EphB2 & AGAATGGTGCCATCTTCCAG & CCTTGAAGGTTCCTGATGGA \\
\hline EphrinB2 & AGGAATCACGGTCCAACAAG & GTCTCCTGCGGTACTTGAGC \\
\hline EphrinA5 & GCTGCTCTTTCTGGTGCTCT & GGGCAGAAAACATCCAGGTA \\
\hline
\end{tabular}


Table 3. Statistical Analysis of Genes modified by Cocaine Treatments and confirmed by qRT-PCR. Statistical significance of the genes candidates modified by cocaine from microarray and confirmed by qRT-PCR (see Fig 4) was evaluated by the two-tailed Student's test (see Methods). $-\mathrm{P} \geq 0.05$; ${ }^{*} \mathrm{P}<0.05$; ** $\mathrm{P}<0.01 ; * * * \mathrm{P}<0.005$.

\begin{tabular}{|c|c|c|c|c|c|c|c|c|c|c|c|c|c|c|c|c|c|c|c|c|c|c|c|c|c|c|c|c|}
\hline & \multicolumn{7}{|c|}{ Hippocampus } & \multicolumn{7}{|c|}{ Nucleus Accumbens } & \multicolumn{7}{|c|}{ Caudate Putamen } & \multicolumn{7}{|c|}{ Ventral Tegmentum Area } \\
\hline & $\mathbf{A}$ & $\mathbf{B}$ & $\mathbf{C}$ & S1 & S2 & S3 & S4 & $\mathbf{A}$ & $\mathbf{B}$ & $\mathbf{C}$ & S1 & S2 & S3 & S4 & $\mathbf{A}$ & $\mathbf{B}$ & $\mathbf{C}$ & S1 & S2 & S3 & $\mathrm{S} 4$ & $\mathbf{A}$ & $\mathbf{B}$ & $\mathbf{C}$ & S1 & S2 & S3 & S4 \\
\hline \multirow{5}{*}{\begin{tabular}{|c|} 
Sema3A \\
Sema3B \\
Sema3C \\
Sema3E \\
Sema3F
\end{tabular}} & - & - & - & - & - & - & - & - & - & - & $*$ & - & - & - & $*$ & - & - & - & - & - & - & - & - & - & - & - & - & - \\
\hline & - & - & ** & - & - & - & - & - & - & $* * *$ & - & - & - & - & - & - & - & - & - & - & - & - & - & - & - & - & - & - \\
\hline & - & - & - & - & - & - & $*$ & - & - & - & - & - & - & - & - & - & - & - & - & - & - & - & - & ** & - & - & - & *** \\
\hline & $*$ & $* *$ & $* * *$ & $*$ & $*$ & $* *$ & $* * *$ & ** & $*$ & * & * & $*$ & * & $*$ & $\begin{array}{l}* * \\
\end{array}$ & * & \begin{tabular}{|l|}
$* *$ \\
\end{tabular} & * & ** & ** & **** & $\begin{array}{l}* * * \\
\end{array}$ & $*$ & $*$ & *** & ** & $*$ & *** \\
\hline & - & - & - & - & - & - & - & **** & - & - & - & - & - & $*$ & - & - & - & - & - & - & \begin{tabular}{|l|l|}
$* *$ \\
\end{tabular} & - & - & - & - & - & - & \begin{tabular}{|l}
$* * *$ \\
\end{tabular} \\
\hline \multirow{3}{*}{$\begin{array}{l}\text { Sema4A } \\
\text { Sema4B } \\
\text { Sema4C }\end{array}$} & - & - & - & - & - & - & - & ** & - & - & - & - & - & - & - & - & - & - & - & - & - & $*$ & - & - & - & - & - & - \\
\hline & - & - & - & - & - & - & - & - & - & $* * *$ & - & - & - & - & - & - & - & - & - & - & - & - & - & $*$ & - & - & - & - \\
\hline & **** & - & - & - & - & - & - & - & - & $* * *$ & - & - & - & - & - & - & $\begin{array}{l}* * * \\
\end{array}$ & - & - & - & - & - & - & - & - & - & - & - \\
\hline \multirow{3}{*}{$\begin{array}{l}\text { Sema4D } \\
\text { Sema4F } \\
\text { Sema4G }\end{array}$} & - & - & - & - & - & - & - & - & - & - & - & - & - & - & $* * *$ & - & - & - & - & - & - & * & - & - & - & - & - & - \\
\hline & - & - & - & - & - & - & $*$ & - & - & - & - & - & - & - & - & - & - & - & - & - & - & - & - & - & - & - & - & \begin{tabular}{|l}
$* * *$ \\
\end{tabular} \\
\hline & $* * *$ & - & - & - & - & - & - & - & - & - & - & - & - & $*$ & $*$ & - & - & - & - & - & $* *$ & $* * *$ & - & - & - & - & - & *** \\
\hline \multirow{5}{*}{$\begin{array}{c}\text { Sema5A } \\
\text { Sema5B } \\
\text { Sema6C } \\
\text { Sema7A } \\
\text { NP-1 } \\
\end{array}$} & - & ** & *** & - & - & - & - & - & - & - & - & - & - & - & - & - & * & - & - & - & - & - & $* * *$ & ** & - & - & - & *** \\
\hline & - & - & - & - & - & - & - & * & - & - & $*$ & - & - & - & * & - & - & - & - & - & - & **** & - & - & $* *$ & - & - & - \\
\hline & - & - & - & $* *$ & - & - & - & - & - & - & $* * *$ & - & - & - & - & - & - & $* * *$ & - & - & - & - & - & - & **** & - & - & - \\
\hline & - & - & - & - & - & - & - & $* * *$ & - & - & - & - & - & - & - & - & - & - & - & - & - & $* * *$ & - & - & - & - & - & - \\
\hline & $*$ & $*$ & $* *$ & - & $*$ & ** & *** & ** & $*$ & $* *$ & - & $*$ & $* *$ & ** & ** & $*$ & *** & - & ** & ** & ** & $*$ & ** & ** & - & $*$ & ** & *** \\
\hline & \multirow{2}{*}{\multicolumn{7}{|c|}{ Hippocampus }} & & & & & & & & & & & & & & & & & & & & & \\
\hline & & & & & & & & \multicolumn{7}{|c|}{ Nucleus Accumbens } & \multicolumn{7}{|c|}{ Caudate Putamen } & \multicolumn{7}{|c|}{ Ventral Tegmentum Area } \\
\hline & $\mathrm{A}$ & $\mathrm{B}$ & $\mathrm{C}$ & S1 & S2 & S3 & S4 & $\mathrm{A}$ & $\mathrm{B}$ & $\mathrm{C}$ & S1 & $\mathrm{S} 2$ & S3 & S4 & $\mathrm{A}$ & $\mathrm{B}$ & $\mathrm{C}$ & S1 & $\mathrm{S} 2$ & S3 & S4 & $\mathrm{A}$ & $\mathrm{B}$ & $\mathrm{C}$ & S1 & $\mathrm{S} 2$ & $\mathrm{~S} 3$ & $\mathrm{~S} 4$ \\
\hline EphA1 & - & - & - & - & - & - & - & - & - & - & - & - & - & - & $* * *$ & - & - & - & - & - & - & - & - & - & - & - & - & - \\
\hline EphA3 & - & - & - & - & - & - & - & $*$ & - & - & - & - & - & - & **** & - & - & - & $* *$ & - & - & - & - & - & - & - & - & - \\
\hline EphA5 & - & - & - & - & - & $*$ & $*$ & - & - & - & - & - & - & - & - & - & - & $*$ & $*$ & $*$ & * & - & - & - & - & - & - & * \\
\hline EphA8 & $*$ & $*$ & $*$ & - & - & $*$ & $*$ & $*$ & $*$ & - & - & $*$ & $*$ & $*$ & $*$ & - & - & - & $*$ & - & $*$ & - & - & - & $*$ & - & $*$ & $*$ \\
\hline EphB1 & - & - & $* *$ & - & - & - & *** & - & - & $* *$ & - & - & - & $* *$ & - & - & $*$ & - & - & - & $*$ & - & - & $*$ & - & - & - & *** \\
\hline EphB2 & - & - & \begin{tabular}{|l|}
$* *$ \\
\end{tabular} & - & - & - & - & - & - & $* *$ & - & - & - & - & - & - & $*$ & - & - & - & - & - & - & $*$ & - & - & - & *** \\
\hline EphB3 & - & - & $*$ & - & - & - & - & - & - & ** & - & - & - & - & - & - & - & - & - & - & - & - & - & - & - & - & - & - \\
\hline EphB4 & - & - & **** & - & - & - & - & - & - & **** & - & - & - & - & - & - & - & - & - & - & - & - & - & - & - & - & - & - \\
\hline EphB6 & - & - & - & - & - & - & - & - & - & $* *$ & - & - & - & - & - & - & - & - & - & - & - & - & - & - & - & - & - & - \\
\hline EphrinA1 & - & - & - & - & - & - & - & - & - & - & - & - & - & - & $* * *$ & - & - & - & - & - & - & * & - & - & - & - & - & - \\
\hline EphrinA3 & - & - & - & - & - & - & - & - & - & - & - & - & - & - & $* * *$ & - & - & - & - & - & - & $\begin{array}{l}* * \\
\end{array}$ & - & - & - & - & - & - \\
\hline EphrinA5 & - & - & - & - & - & - & - & - & - & - & - & $*$ & - & ** & - & - & - & - & - & - & - & - & - & - & - & - & - & $*$ \\
\hline EphrinB2 & - & - & - & - & - & - & $* * *$ & - & - & - & - & - & - & $* *$ & - & - & - & - & - & - & $* *$ & - & - & - & - & - & - & *** \\
\hline EphrinB3 & - & - & - & - & - & - & $* * *$ & - & - & - & - & - & - & $*$ & - & - & - & - & - & - & $*$ & - & - & - & - & - & - & $*$ \\
\hline
\end{tabular}

